\title{
Dynamic control of urban sewer systems to reduce combined sewer overflows and their
} adverse impacts

(1)

\author{
Upaka Rathnayake $^{1 *}$ and A.H.M. Faisal Anwar ${ }^{2}$ \\ ${ }^{1}$ Department of Civil Engineering, Faculty of Engineering, Sri Lanka Institute of Information \\ Technology, New Kandy Road, Malabe, Sri Lanka \\ ${ }^{2}$ Department of Civil Engineering, Curtin University, GPO Box U1987, Perth WA 6845, \\ Australia \\ *Corresponding email: upakasanjeewa@gmail.com / upaka.r@sliit.lk
}

10

\section{Highlights}

- Optimal control model is developed to control the existing combined sewer networks.

- Multi-objective optimization techniques are applied to the control model to minimize the pollution load to receiving water and the cost of wastewater treatment together with cost of pump operation.

- Spatial and temporal variations of flow and water qualities in stormwater runoff are considered to the model.

- The model can control the gates dynamically with respect to the time, based on the feedback from the control settings of the previous time-step. 


\section{Abstract}

24 Sewer network planners use control algorithms, based on optimization techniques, to control

25 urban wastewater systems. These control algorithms have been used to ease the stress on the 26 sewer networks and then, to reduce or to minimize the combined sewer overflows (CSOs). CSOs

27 are not only risking human health but also adversely affecting the aquatic lives. Therefore, many

28 cities try to avoid CSOs. However, this cannot be done to the perfect level due to the capacity

29 limitations of the existing combined sewer networks. In addition, climate variabilities have

30 caused unpredictable precipitation increments and therefore, the control is extremely difficult.

31 Therefore, considering the spatial and temporal variations of runoffs and qualities of stormwater

32 generated from the precipitation, an enhanced optimal control algorithm is illustrated in this

33 paper to control the existing combined sewer networks. Minimizing the pollution load to the

34 receiving water and minimizing the cost of wastewater treatment and pump operation are the two 35 objective functions in the developed optimization algorithm. The algorithm was then 36 successfully applied to a real-world combined sewer network in Liverpool, United Kingdom.

37 Results reveal that the developed optimal control model is capable of handling the dynamic 38 control settings of combined sewer system to minimize the two objective functions 39 simultaneously. With a little computational appreciation, the developed optimal control model 40 can be well-used in the real-time control of combined sewer networks.

42 Keywords: Combined sewer overflows (CSOs), dynamic control, evolutionary algorithms, multi-objective optimization, orifice gate openings, pumping cost 


\section{Introduction}

47 In many countries, the existing sewer networks are not designed to handle the collective

48 stormwater and wastewater during the stormy periods (Zhao et al., 2017). Because of this 49 capacity limitation, combined sewer overflows (CSOs) occur. Moreover, on-going climate 50 variability and climate changes may cause intensified precipitation events in some areas which 51 may also lead to frequent CSOs (Tavakol-Davani et al., 2016; Dirckx et al., 2017; Jean et al., 52 2018; Zhang et al., 2018a). Though, CSOs sometimes prevent flooding in important places 53 (Zhao et al., 2017) but it can bring significant environmental risk if they are not properly 54 controlled (Jalliffier-Verne et al., 2016; Madoux-Humery et al., 2016; Brokamp et al., 2017).

55 The receiving water bodies are in danger due to sudden accumulation of pollution loads from 56 CSOs (Zhang et al., 2018b; Schertzinger et al., 2019; Soriano and Rubió, 2019). Many 57 researchers conducted detailed research on identifying the various pollutants in CSOs, impact of 58 CSOs on ecosystem and drinking water qualities (Gasperi et al., 2012; Jalliffier-Verne et al., 59 2016; García et al., 2017; Hermoso et al., 2018; Wei et al., 2019). García et al., (2017) have 60 experimentally obtained the pollutographs for two cities in Spain along the lines of CSOs. 61 Rathnayake (2013) also derived pollutographs for various water quality constituents considering 62 spatial and temporal variations. Again, the CSOs can cause severe urban flooding (Meneses et $63 a l ., 2018)$ at unexpected locations and reduce the wastewater treatment plants' efficiency (Zhang 64 et al., 2018b). Therefore, minimizing CSOs in urban areas is an important task for many 65 municipal councils. These may be done by using structural or non-structural measures. The 66 physical constructions developed to reduce the CSOs are the structural measures in controlling 67 CSOs (for example, underground tunnels to store combined sewer flows in stormy days). 68 However, Non-structural measures do not involve any physical constructions but they involve 
69 the usage of knowledge and experiences to develop various policies and control approaches to 70 reduce the CSOs in existing sewer networks. The financial capabilities and disturbances to the

71 habitants have limited the structural measures in minimizing the CSOs (Zhang et al., 2018a).

72 Thus, non-structural measures are given a higher priority in today's world. Therefore, non-

73 structural measures, including control algorithms based on optimization theories, are becoming

74 popular (Zimmer et al., 2015 \& 2018). Nevertheless, structural measures are still used when the 75 space and financial capacities are permitted (Nasri and Haynes, 2015).

76 Even though, the non-structural measures are used to overcome the issues from CSOs, multiple 77 interactions in various sub-systems such as, catchments, sewer systems, wastewater treatment 78 plant and receiving water bodies make the control of urban wastewater system a greater 79 challenge (Saagi et al., 2016 \& 2018). In addition, the dynamic behavior of flow and wastewater 80 quality in sewer systems make the scenario more complex (Rathnayake and Tanyimboh, 2015). 81 Therefore, a holistic solution for the optimal control of combined sewer system is still to be 82 tabled.

83 Many researchers showcased the usage of green infrastructure (GI) as a measure to reduce the 84 CSOs (Lucas and Sample, 2015; Sørup et al., 2016; Tao et al., 2017; Talebi and Pitt, 2019). 85 Green infrastructure is an approach to balance the natural water cycle using engineered or non86 engineered techniques of water management. Some other researchers have introduced model 87 predictive control (MPC) approaches to minimize CSOs (Joseph-Duran et al., 2015; Zhao et al., 88 2017; Snodgrass et al., 2018). Zimmer et al., (2015) presented an MPC model to reduce the 89 CSOs for a deep-tunnel sewer system. They have further extended their work (Zimmer et al., 90 2018) to explore the efficiency and effectiveness of different MPC approaches. 
91 Storage tanks in combined sewer systems are utilized properly as another solution to CSOs. The

92 overall idea of this method is to reduce the CSOs volume flow rates. Therefore, these control

93 models are based on the volumetric measures. Models based on storage tanks have been applied

94 as case studies in many places (Ryu et al., 2015; Hermoso et al., 2018; Georgaki et al., 2018;

95 Wang and Guo, 2018; Zhang et al., 2018a; Zhang et al., 2018b). These studies include the

96 optimal sizing and optimal locating of storage tanks (Hermoso et al., 2018).

97 Real time control (RTC) plays a major role in sewer network control. The control algorithms

98 continuously get the feedback from the sewer system and adjust the settings accordingly.

99 However, this is not easily applicable for all combined sewer systems, due to the logistical

100 issues. Nevertheless, many researchers tried to implement RTC strategies to combined sewer

101 systems as a holistic solution for CSOs (Enterm et al., 1998; Dirckx et al., 2017; Mahmoodian et

102 al., 2017; Meneses et al., 2018; Congcong et al., 2019). However, some of these simplified RTC

103 systems can be found in many places to measure the water quality constituents which may

104 include Graz in Austria (Hofer et al., 2018), Copenhagen in Denmark (Vezzaro et al., 2014),

105 Lodz in Poland (Brzezińska et al., 2016), Trondheim (Weinteich et al., 1997) and Fredrikstad

106 (Nie et al., 2009) in Norway and Wilhelmshaven (Seggelke et al., 2013) and Odenthal (Erbe et

107 al., 2002) in Germany. These RTC models in sewer systems are simple but fast in computation

108 (Mahmoodian et al., 2017). But dynamic control based on receiving water qualities and

109 minimizing CSOs is yet to be presented. Nevertheless, optimization techniques including multi-

110 objective optimization are widely used in these control algorithms (Mauricio-Iglesias et al.,

111 2015; Morales et al., 2015; Morales, 2016; Ogidan et al., 2016). Therefore, there is a need for a

112 holistic approach to minimize the CSOs and maximize the receiving water qualities considering

113 the dynamic spatial and temporal behaviors of the sewer systems and its attributes. This paper 
114 presents a novel dynamic control algorithm based on the pollution control in receiving water due

115 to CSOs and overall treatment and pumping cost of the sewer network. The control algorithm is 116 based on the multi-objective optimization function to minimize both pollution load to receiving 117 water and overall cost in sewer system simultaneously. In addition, it is capable of presenting 118 dynamic control strategies based on the feedback, unlike most other rule-based control strategies.

119 The temporal and spatial variation of pollutants in stormwater runoff is also highly important in 120 finding the pollution load to the receiving water from various locations (Anne-Sophie et al., 121 2015; Müller et al., 2017). Therefore, the presented method is capable of handling both spatial 122 and temporal distributions of stromwater flow rates and also the various pollution concentrations 123 in stormwater. The developed novel dynamic control algorithm was successfully tested to the 124 real world combined sewer network and promising results are presented.

\section{Hydraulics of the storage tanks in sewer networks}

126 Storage tanks in sewer networks play an important role in minimizing possible CSOs. They store 127 wastewater during the stressed (stormy) periods and release back to the sewer network in non128 stressed (dry) periods. The storage tanks are very common in combined sewer networks and can 129 be categorized into on-line storage tanks or off-line storage tanks (Read and Vickridge, 1997; 130 Read 2004). The storage tank category is mainly selected based on the surrounding land areas 131 and land uses of the sewer networks. If the land area is crowded or highly valuable, the sewer 132 network planners can decide to have the storage tank at a faraway location where the land area is 133 not much valuable. This process requires additional hydraulic components such as pumps to have 134 two directional flows. If surrounding land area is not so costly, the storage tanks can be placed 135 nearer to the sewer system, and thus the control is easy and it may not require a pump. Therefore, 
136 a complex larger sewer network may have both features of on-line storage tanks and/or off-line 137 storage tanks.

138 On-line storage tanks are attached to the CSO chambers. The schematic diagrams of on-line and 139 off-line storage tanks are shown in Figure. 1. The on-line storage tanks start to fill $\left(q_{s}\right)$ when the 140 inflow $\left(I_{i, t}\right)$ is more than the maximum allowable through flow $\left(Q_{i, t}\right)$ to the sewer network 141 (Figure 1a). A throttle is usually used to control the discharge from the on-line storage tank.

142 When the water level in the storage tank reaches to the maximum, the flow to the storage tank 143 from sewer chamber is blocked. Therefore, the system allows the sewer chamber to have 144 overflows $\left(O_{i, t}\right)$. However, when the water level in sewer chamber reduces to a controllable 145 level, the bottom orifice combining storage tank and sewer chamber is opened and the stored 146 flow is easily transferred back to the sewer chamber.

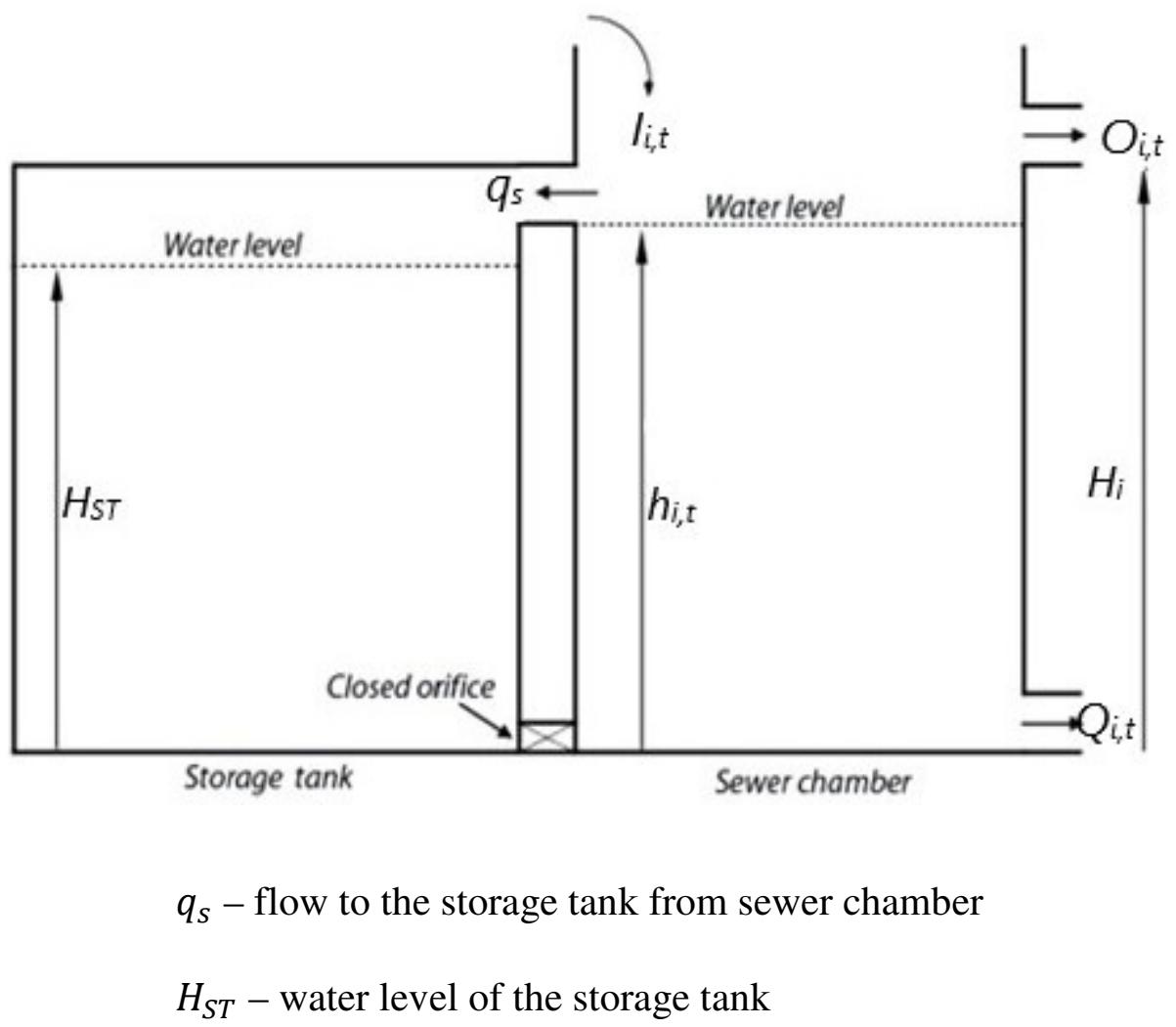


$h_{i, t}$ - water level in the sewer chamber

$H_{i}$ - spill level of the sewer chamber

$I_{i, t}$ - catchment inflow to $i^{\text {th }}$ interceptor node

$O_{i, t}-$ flow from $i^{\text {th }}$ sewer chamber to $i^{\text {th }}$ interceptor node

$Q_{i, t}-$ combined sewer overflow discharge at $i^{t h}$ interceptor node

(a)

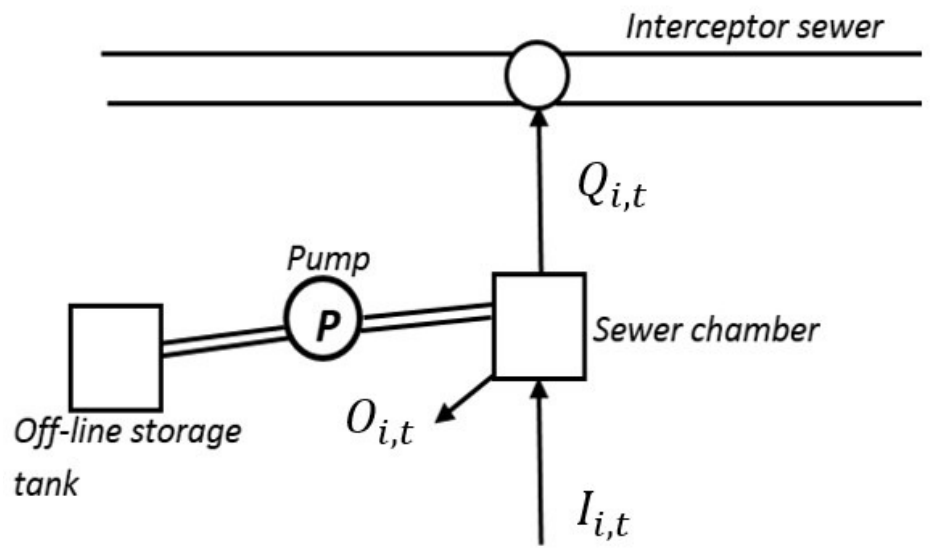

(b)

147

148 Figure 1. Schematic diagram of sewer chamber with (a) on-line storage tank and (b) off-line

149 storage tank

150

151 Figure $1 \mathrm{~b}$ shows the schematic diagram of the off-line storage tank in the combined sewer

152 systems. Unlike the on-line storage tanks, the off-line storage tanks are physically separated from

153 CSO chambers. The off-line storage tanks are placed far away from the sewer chambers. When

154 the land area around sewer chambers are highly valuable, the designers move the on-line storage

155 tanks to off-line storage tanks. Therefore, storage tanks in sewer system in rural areas may be

156 preferable than the urban areas. 
157 The flow is diverted to the off-line tank from the sewer chamber during the stormy seasons. This can either be via gravity fed pipes or pumped pipes. During unstressed periods the stored wastewater can be released back to the sewer chamber. However, the releasing of wastewater must be via pumped pipes if wastewater was diverted via gravity fed pipes or vice versa. Therefore, the off-line storage tank always comes with a hydraulic pump, which add an additional cost to the operation. But the extended pipeline (away from the sewer chamber) in offline storage tank also gives an additional storage facility during the stormy period.

\section{Mathematical formulation for the optimization problem}

This section presents a development of an algorithm to control the combined sewer systems dynamically. The dynamic control is based on the feedback from each time-steps by solving the following multi-objective optimization algorithm. The developed algorithm considers two objective functions which are time, flow and water quality dependent.

\subsection{Objective functions}

The first objective function $\left(F_{1}\right)$ is formulated to minimize the pollution load discharges to the natural water from the CSOs at each time-step. The mathematical expression of the first objective function is given in the Equation 1.

$$
F_{1}=\text { Minimize } \sum_{i=1}^{n} P_{i}
$$

where $P_{i}$ is the pollution load discharged from $i^{\text {th }}$ sewer chamber at a given time-step and $n$ is the number of CSOs or number of sewer chambers. $P_{i}$ is calculated using the effluent quality index (EQI) defined to each CSO. EQI is a single index to measure the pollution load. It integrates 
179 several pollutants together including the concentrations of total suspended solid (TSS), 180 biochemical oxygen demand $(B O D)$, chemical oxygen demand $(C O D)$, nitrates and nitrites $181\left(N O_{X}\right)$, total Kjedahl nitrogen $(T K N)$ and total phosphorus $(T P)$. Equation 2 gives the 182 mathematical expression for the EQI.

183

$$
P_{i}=E Q I_{i}=\frac{1}{1000\left(t_{f}-t_{0}\right)} \int_{t_{0}}^{t_{f}}\left(2 C_{T S S}+C_{C O D}+2 C_{B O D}+20 C_{N O X}+20 C_{T K N}+100 C_{T P}\right) Q_{e}(t) d t
$$

where $Q_{e}(t), t_{f}$ and $t_{0}$ are the combined sewer overflow rate, final and initial time, respectively.

$186 C_{T S S}, C_{C O D}, C_{N O X}, C_{B O D}, C_{T K N}$ and $C_{T P}$ are the concentrations of total suspended solids, chemical 187 oxygen demand, nitrates and nitrites, five-day biochemical oxygen demand, total Kjeldahl 188 nitrogen and total phosphate, respectively and measured in milligram per liters $(\mathrm{mg} / \mathrm{L})$. 189 Numerical values in front of the concentrations are the weightages used to integrate the different 190 pollutants to build up the pollution load. More information on this effluent quality index can be 191 found in Benedetti et al., (2006), Kim et al., (2009) and Rathnayake (2018).

192 The second objective function $\left(F_{2}\right)$ is formulated to minimize the treatment plant cost and the 193 operational cost of pumps in the sewer system at a given time-step. The mathematical behavior 194 of the objective function is presented in Equation 3. 195

$$
F_{2}=\operatorname{Minimize}\left(C_{T}+C_{P}\right)
$$

197 where $C_{T}$ (€/year) is the wastewater treatment plant cost and the $C_{P}$ (€/year) is the operational 198 cost of pumps in sewer system. $C_{T}$ and $C_{P}$ are based on the wastewater flowrate. For example, 
199 for a particular system, the pump cost is calculated based on the wastewater volume, which is

200 pumped from the hydraulic pump. Cost of treatment plant can be expressed according to the

201 Equation 4.

202

$$
C_{T}=\left\{\begin{array}{lr}
1642353 \times q_{T}^{0.659}, & q_{T} \leq 3 q_{d r y} \\
1891.154 \times q_{d r y}^{0.659}+7.84 \times q_{T}-3.38 \times q_{d r y}+7584, & 6 q_{d r y} \geq q_{T} \geq 3 q_{d r y} \\
1891.154 \times q_{d r y}^{0.659}+3.38 \times q_{d r y}+7584, & 6 q_{d r y} \leq q_{T}
\end{array}\right.
$$

203

204 where $q_{T}\left(\mathrm{~m}^{3} / \mathrm{s}\right)$ and $q_{T d r y}\left(\mathrm{~m}^{3} / \mathrm{s}\right)$ are the treated wastewater volume flowrate and the dry 205 weather flowrate, respectively. More information about this treatment plant cost function can be 206 found in Rathnayake and Tanyimboh (2015) and Rathnayake (2013). The above presented 207 treatment cost function looks at the total operational cost of wastewater treatment plant 208 including, wastewater treatment cost, personal cost, energy cost, maintenance cost, etc. In 209 addition, the treatment cost formula can be modified time-to-time using a simple coefficient 210 based on the considered country's economy.

211 The pump operational cost $\left(C_{P}\right)$ is formulated as a function of pumped wastewater volume flow 212 rate $\left(Q_{P}\right)$ given in Equation 5. The equation developed is based on the power required to pump 213 the wastewater to the required head and it is a function of the pumped wastewater volume flow 214 rate.

215

$$
C_{P}=K \frac{\rho g H_{P}}{\eta_{\text {pump }} \eta_{\text {motor }} t_{P}} Q_{P}
$$


217 where $K, \rho, g, H_{P}, \eta_{\text {pump }}, \eta_{\text {motor }}$ and $t_{P}$ are the cost for unit power in electricity, density of

218 wastewater, gravitational acceleration, head given to the wastewater by the pump, efficiency of

219 the pump, efficiency of the motor and pump operation time, respectively. More information on

220 the development of this generic pump operational cost can be found in Rathnayake (2018).

221

\subsection{Constraints}

223 The above stated two objective functions $\left(F_{1}\right.$ and $\left.F_{2}\right)$ are under a set of constraints. In other 224 words, the solutions of these two objective functions must be limited to the given set of 225 constraints. The sewer system hydraulically satisfies the continuity equation. Figure 2 shows the 226 schematics of the node in the sewer network. Referring to the Figure 2, the continuity equations 227 can be illustrated as shown in Equations 6 - 8 .

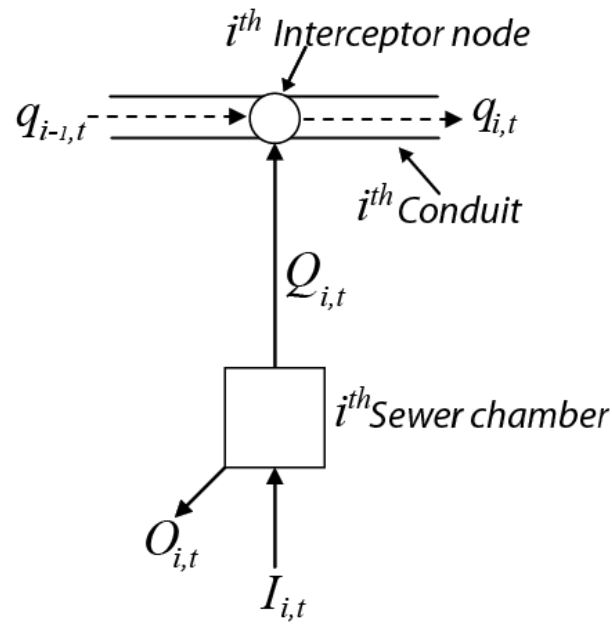

$I_{i, t}-$ catchment inflow to $i^{\text {th }}$ interceptor node 


$$
\begin{gathered}
Q_{i, t}+q_{i-1, t}-q_{i, t}=0 \\
A_{C} \frac{\Delta h_{i, t}}{\Delta t}=I_{i, t}-Q_{i, t} ; \quad h_{i, t}<H_{i} \\
A_{C} \frac{\Delta h_{i, t}}{\Delta t}=I_{i, t}-Q_{i, t}-O_{i, t} ; \quad h_{i, t}>H_{i}
\end{gathered}
$$

where $A_{C}$ is the surface area of the sewer chamber. In addition, the sewer system is under the capacity constraints. They are introduced to satisfy the non-silting and non-scouring flow rates

242 (velocities) in sewer network. These capacity constraints are given in Equation 9.

$$
0 \leq q_{i, t} \leq q_{\max , i}
$$

245 where $q_{i, t}$ and $q_{\max , i}$ are the flow rates inside the $i^{\text {th }}$ sewer conduit at time $t$ and the maximum 246 allowable flow rate in $i^{\text {th }}$ sewer conduit, respectively.

\subsection{Solution technique for the optimization problem}

249 Multi-objective optimization problems can be solved in various ways (Marler and Arora, 2004).

250 Weighted global criterion method (Zhang and Shivpuri, 2009; Costa et al., 2011; Zhao et al., 
251 2012), weighted sum method (Kim and de Weck, 2004; Marler and Arora, 2009; Wang et al., 252 2018), Lexicographic method (Sun et al., 1999; Jee et al., 2007; Aghaei et al., 2011), weighted 253 min-max method (Wang et al., 1996; Shimoda et al., 1996; Singh, 2002), exponential weighted 254 criterion (Carpinelli et al., 2014 ; Kang et al., 2014), weighted product method (Wang et al., 255 2010), goal programming methods (Charnes and Cooper, 1977; Hu et al., 2007), bounded 256 objective function method (Abo-Sinna and Baky, 2007; Zheng et al., 2011), physical 257 programming methods (Qiu et al., 2011; Yuan et al., 2014) and generic algorithms (Grefenstette, 258 1986; Srinivas and Deb, 1994) are several methods in the literature to obtain solutions from 259 multi-objective optimization problems. A genetic algorithm-based optimization solver was used 260 to obtain the optimal solutions for the developed multi-objective optimization problem in this 261 study. Despite the other available approaches, a genetic algorithm solver was selected due to the 262 complexity of the optimization problem.

263 Genetic algorithms mimic the biological evolution in searching for the minimum or maximum 264 solutions (Marler and Arora, 2004). They continuously update the population of solutions in each 265 step. Crossover and mutation processes are introduced by most of the generic algorithms to 266 produce new offspring (children) from the parent population. More information on the process of 267 genetic algorithms can be found in Davis (1991).

268 Two objective functions given in Equations 1 and 3 were solved in the genetic algorithms' 269 environment. However, these objective functions were treated independently without simplifying 270 them to one objective function using relative weights. As it was explicitly stated in Equations 2, 2714 and 5, the two objective functions vary with time and space. Therefore, the temporal and 272 spatial variation of flow rates and concentrations of various water quality constituents are 273 included. The parameters which are used to calculate the objective functions $\left(F_{1}\right.$ and $\left.F_{2}\right)$ were 
274 directly obtained from the complete hydraulic simulations and water quality simulations of the

275 sewer network. Therefore, the hydraulic simulations and water quality simulations were carried

276 out for number of function evaluations (for example 10000 function evaluations) and more

277 importantly, the full hydraulic simulations were carried out using Saint-Venant equations.

278

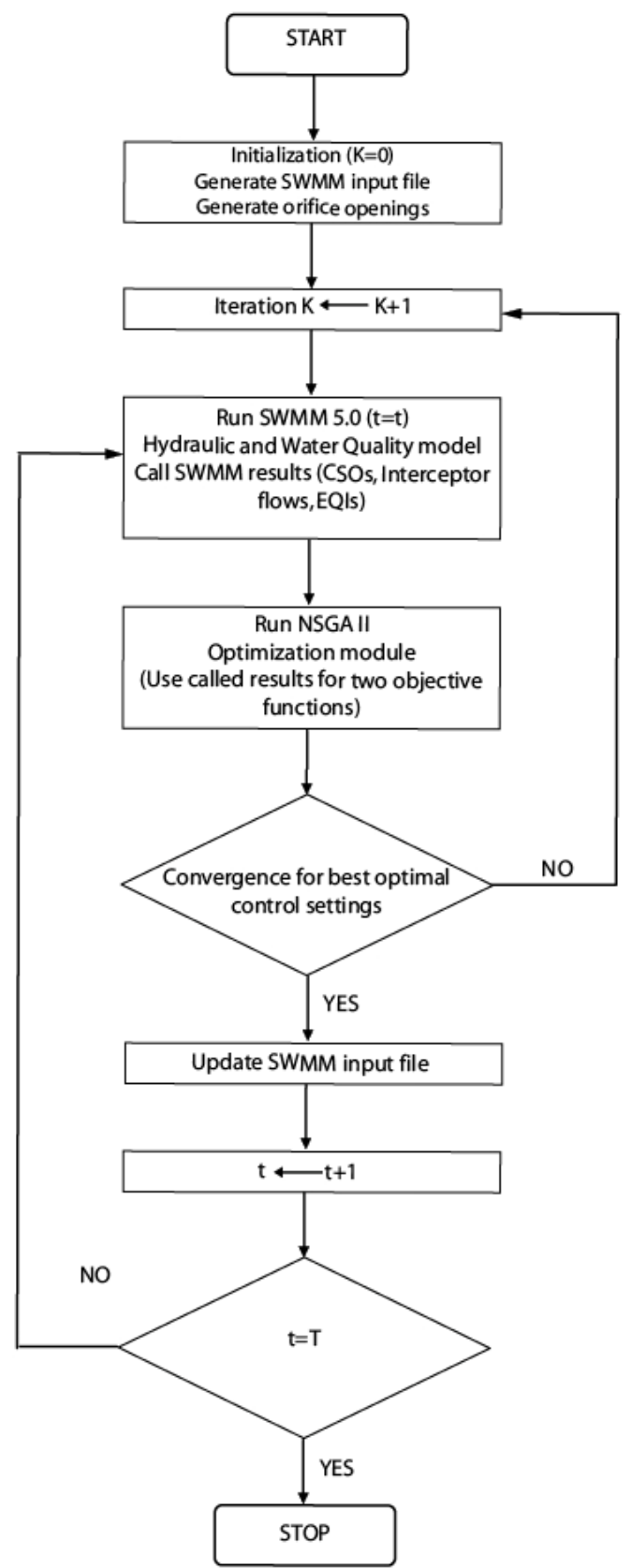


Figure 3 Flowchart to the solution algorithm for the developed multi-objective optimization

problem

282

283

Hydraulic model, SWMM 5.0 (Rossman, 2009) and multi-objective optimization module, NSGA

284

II (Deb et al., 2002) were linked together to obtain the above stated parameters (inputs of the

285

multi-objective optimization problem). SWMM 5.0 was developed by the U.S. Environmental

286

Protection Agency (USEPA) and applied to many real-world examples all over the world

287 (Berndtsson and Niemczynowicz, 1988; Rodriguez et al., 2003; Maneta et al., 2007; Leisenring

288

and Moradkhani, 2012; Brunetti et al., 2016). The model is capable of conducting simulations

289

and analysis to stormwater networks and sewer network to satisfy the hydrological, hydraulics

290

and water quality requirements. On the other hand, NSGA II optimization algorithm is

291

extensively used in real-world optimization problems including water resource management

292

issues (Alizadeh et al., 2017; Bekele and Nicklow, 2007; Chang and Chang, 2009; Lei et al.,

293 2018; Naserizade et al., 2018).

294 A set of orifices with gates placed in the CSO chambers were used to control the flow in the combined sewer system. Therefore, the decision variables of the developed multi-objective optimization problem are the gate openings of the orifices at different time-steps. The flowchart

297 to the solution algorithm is presented in Figure 3. The gate openings in the orifices for the first 298 time-step (0 - 15 minutes) were randomly generated in NSGA II. Then, a full hydraulic 299 simulation including water quality of the wastewater was carried out inside the SWMM 5.0 300 hydraulic model. The results from the simulation were fed to the NSGA II optimization 301 algorithm and the two objective functions $\left(F_{1}\right.$ and $\left.F_{2}\right)$ were calculated accordingly. Then, the 302 optimization algorithm was run to identify the optimal solutions. Depending on the sewer 303 network controller, one optimal solution was selected from the Pareto optimal front and the 
control settings for that optimal solution were obtained. Those control settings (gate openings) were then, used as the input data for first time step in the hydraulic model for the second timestep (15 - 30 minutes) optimization process. The process was carried out for the whole storm

307 period and control settings were obtained. Finally, sets of orifice gate openings were presented 308 and these control settings can be used by the sewer network controllers.

\section{Real world application}

311 A real-world combined sewer network in Liverpool, United Kingdom was selected to test the 312 developed dynamic control model. The interceptor sewer network (around $3200 \mathrm{~m}$ long) given 313 by Thomas et al. $(1999,2000)$ and Thomas $(2000)$ was further modified to incorporate the 314 objective functions $\left(F_{1}\right.$ and $\left.F_{2}\right)$. These modifications include an introduction of several storage 315 tanks (both on-line and off-line) and a hydraulic pump (P) to the off-line storage tank (T10). 316 More details about these modifications can be found in Rathnayake (2018). The schematic 317 diagram for the modified interceptor sewer network is given in Figure 4.

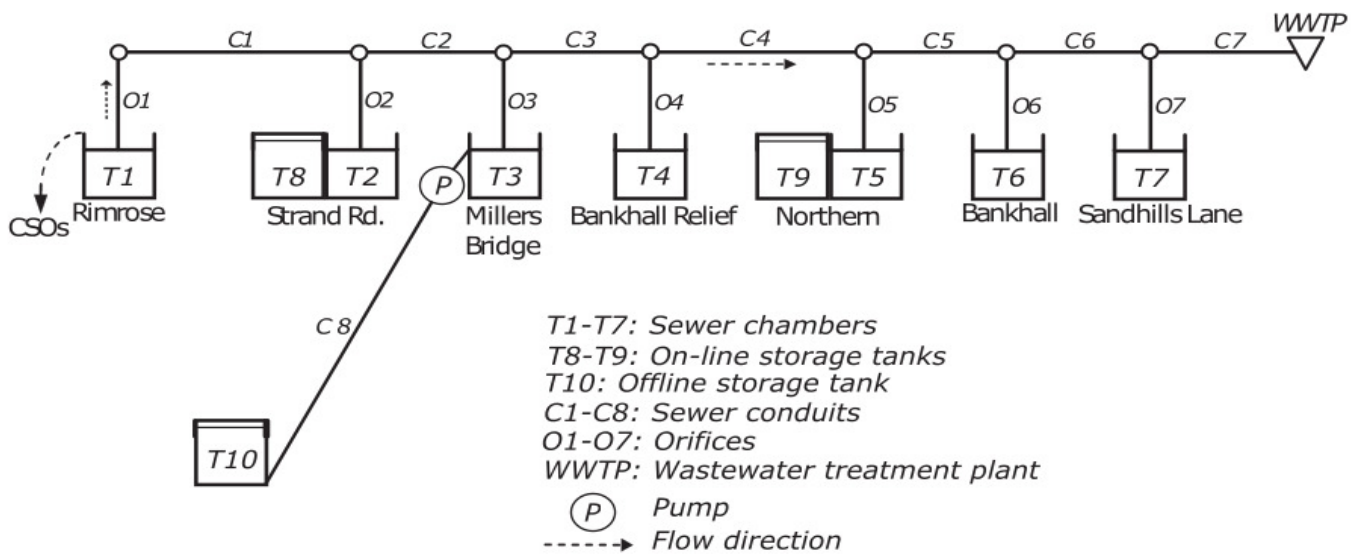

Figure 4 Schematic diagram of interceptor sewer 
321 The on-line storage tanks ( $T 8$ and $T 9$ ) start to fill automatically when the wastewater level in the 322 corresponding sewer chambers ( $T 2$ and $T 5$, respectively) reaches the maximum capacities. The 323 on-line storage tanks stop the inflow wastewater, when they reach their maximum capacities. 324 Therefore, the on-line storage tanks do not allow any CSOs. The stored wastewater can be 325 released back to the sewer system at the lower stressed periods. The control settings of the off326 line storage tank (T10) are slightly different from the on-line storage tanks. When the wastewater 327 level reaches to the spill level of the sewer chamber (T3), the wastewater is pumped to the off328 line storage tank. However, the pump stops its operations when the off-line storage tank reaches 329 to the maximum capacity. However, the stored wastewater is released back to the sewer system 330 in a less stressed period under the gravity. These control settings in the storage tanks and pump 331 were done using the control rules of the hydraulic model.

332 The wastewater flows through the conduits ( $C 1$ to $C 7$ ) are constrained according to the Equation 333 9. The flows through $C 1$ to $C 3$ were kept at $3.26 \mathrm{~m}^{3} / \mathrm{s}$ and those of $C 4$ to $C 7$ were kept at 7.72 $334 \mathrm{~m}^{3} / \mathrm{s}$. More details about the dimensions of the sewer chambers and conduits can be found in 335 Rathnayake $(2013,2018)$. T10 off-line storage tank was placed $2 \mathrm{~km}$ away from the 336 corresponding sewer chamber, $T 3$. The elevation difference from $T 3$ to $T 10$ is $21 \mathrm{~m}$ and the 337 chamber and the off-line storage tank are connected by $0.2 \mathrm{~m}$ diameter, $2000 \mathrm{~m}$ long conduit. 338 Therefore, a pump $(P)$ was introduced to allow the wastewater flow from $T 3$ sewer chamber to $339 \quad T 10$ off-line storage tank. The pump automatically starts and pumps water from T3 to T10 when 340 the wastewater level in $T 3$ reaches to its spill level $(6 \mathbf{~ m})$. The pump automatically stops when 341 the wastewater in the $T 10$ reaches to its maximum capacity and also if the wastewater level in $T 3$ 342 sewer chamber reduces to an acceptable level (4 $\mathbf{~ m ~ l e v e l ) . ~ T h e s e ~ a u t o m a t e d ~ c o n t r o l s ~ w e r e ~ c o d e d ~}$ 343 inside the SWMM 5.0 hydraulic model using the pump control rules. 
344 Stormwater inflows from seven different catchments were fed to the sewer chambers. The 345 catchment names are listed at corresponding sewer chambers (Figure 4). They are Rimrose, 346 Strand Road, Millers Bridge, Bankhall Relief, Northern, Bankhall and Sandhills Lane. Five 347 different land-uses (residential, industrial, agricultural, mid urban and commercial) were 348 assigned to these catchments. More details on the catchments and their land-uses can be found in 349 Rathnayake (2013). Stormwater runoff includes runoff hydrographs from 2.5 hours storms for 350 each catchment and pollutographs for the corresponding runoff hydrographs. TSS, COD, BOD, $351 T K N, N O_{X}$ and $T P$ pollutographs were fed to each sewer chamber from the corresponding 352 catchments. Therefore, the sewer chambers have inputs of spatial and temporal variations of 353 runoffs and six different pollutographs. In addition, the flow rates from dry weather flows and 354 the corresponding concentrations of pollution constituents were fed. More information on these 355 inputs to the sewer chambers can be found in Rathnayake $(2013,2018)$ and Rathnayake and 356 Tanyimboh (2015).

357 Using the sewer flow dynamics in flow rates and wastewater qualities stated above, the 358 developed multi-objective optimization algorithm was run to obtain the optimal solutions $\left(F_{1}\right.$ and $\left.359 F_{2}\right) .10,000$ function evaluations for one time-step $(10,000$ hydraulic and water quality 360 simulations per one time-step) were carried out using the real coded NSGA II optimization 361 algorithm. The gates introduced at sewer chambers were controlled according to the optimization 362 algorithm based on the pollution load to the receiving water and the total cost of the system. 363 Therefore, the gates of the sewer networks were controlled dynamically (with time and space); 364 however, according to the solutions from the developed multi-objective optimization approach. 365 Real coded optimization algorithm generates solutions in real numbers. This is important in gate 366 controls as gate openings can be any value in between the minimum (fully closed) and maximum 
367 (fully opened). Population sizes of 100 for 100 generations were chosen for the optimization

368 process. The crossover probability was kept at 0.9 (Deb et al., 2002); however, different 369 mutation probabilities were tested while calibrating the algorithm. Several random seeds were 370 used for random runs for each time-step to check the convergence of the optimization algorithm.

371 The optimization algorithm was initially run for the first time-step (0-15 minutes) and then, two 372 extreme solutions were selected for the further analysis. They were minimum cost solution and 373 the minimum pollution load solution. The gate openings were obtained for these two solutions 374 and fed to obtain the two optimal corresponding solutions for the next time step. Similarly, 375 optimal control settings for the other time steps (15 minutes by 15 minutes) until the end of the 376 storm were obtained for the two extreme solutions (minimum cost and minimum pollution load).

377 These simulations were carried out in a personal computer (Intel ${ }^{\circledR}$ Core $^{\mathrm{TM}} \mathrm{i} 3$ ) which has 3.40 $378 \mathrm{GHz}$ and 4 GB RAM. The simulation times were about 10-50 minutes.

\section{Results and discussion}

380 Results and discussion section is divided into several subsections to illustrate the results in detail.

381 It starts with the optimization results for the time-step (0-15 minutes) and identified two potential 382 optimal solutions to proceed for the dynamic optimization process. Results of the overall 383 robustness of the developed algorithm is then presented. Next, the optimal control settings of the 384 gates are presented to illustrate the dynamic behavior of the control in the time axis. Finally, the 385 hydraulic verification results are presented to verify the developed multi-objective optimization 386 model in control of the combined sewer system.

387 As it was stated in the preceding paragraph, the optimization simulations were carried out for two different solutions; the minimum pollution load solution and the minimum cost solution until the end of the storm runoff. However, the optimization simulations were performed at 15 
390 minutes time steps; thus, the control settings (gate openings) can be obtained in the intervals of 39115 minutes until the end of storm. The simulations started at $0-15$ minutes and then, proceeded 392 for the next 15 minutes.

395 Pareto optimal front for the first time-step for 0-15 minutes is shown in Figure 5. The shape of the Pareto optimal front clearly presents minimizing behavior of the two objective functions.

397 Two extreme solutions (minimum pollution load and minimum cost) were selected for the 398 optimization process for the 15-30 minutes time-step. These two extreme solutions are shown as $399 \mathrm{MP}_{\mathrm{t} 1}$ (minimum pollution load solution at first time step) and $\mathrm{MC}_{\mathrm{t} 1}$ (minimum cost solution at 400 first time step) in Figure 5.

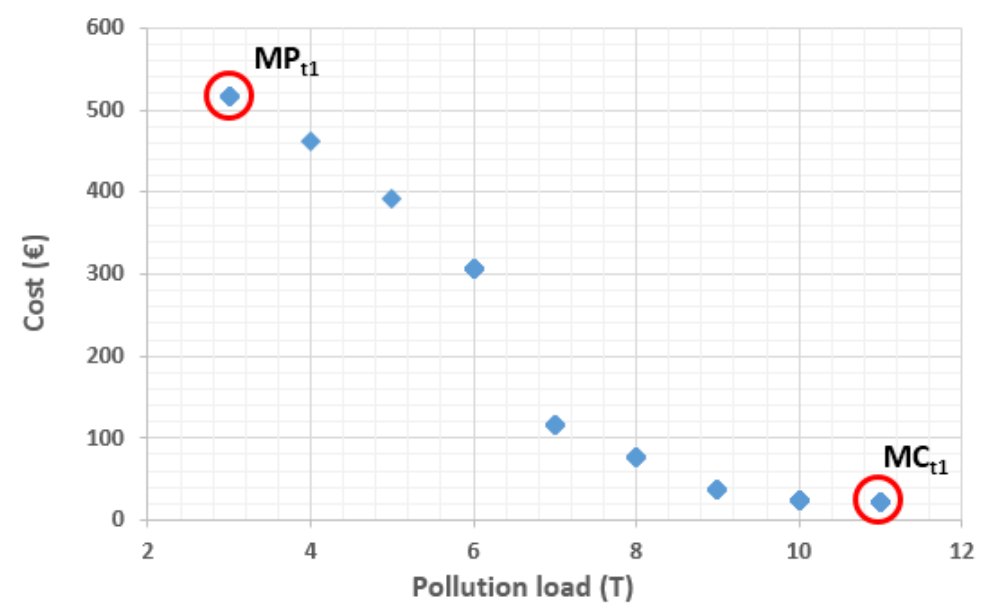
minutes time-step, the dynamic optimization process was carried out for the minimum pollution 405 load and minimum cost solutions for the total period of the storm ( 2 hours and 30 minutes). The 406 Pareto optimal fronts obtained for minimum cost solution at different time-steps for the total 
407 storm period are exhibited in Figures 6a-i. As it was stated in the "Solution technique for the 408 optimization problem" and "Real world application" sections, the control settings from a 409 particular time-step for the minimum cost were used as the data to the next time-step 410 optimization process. For example; control settings for $\mathrm{MC}_{\mathrm{t} 2}$ was used in finding the control 411 settings for $\mathrm{MC}_{\mathrm{t} 3}$.

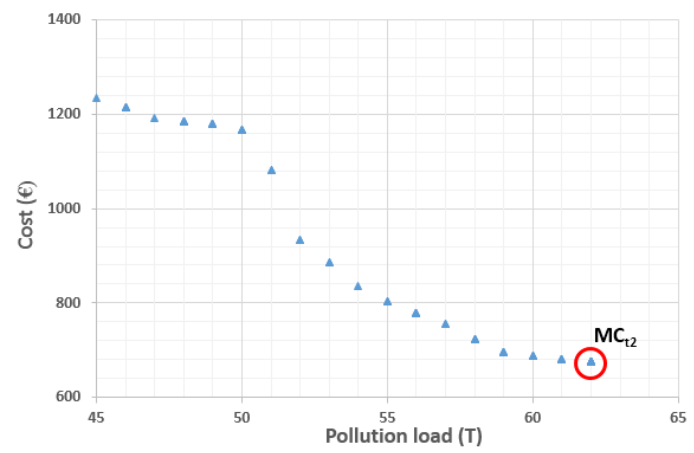

(a) For 15-30 minutes

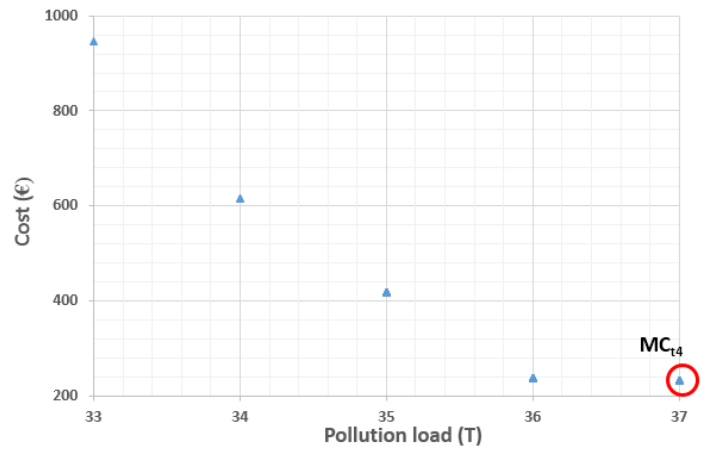

(c) For 45-60 minutes

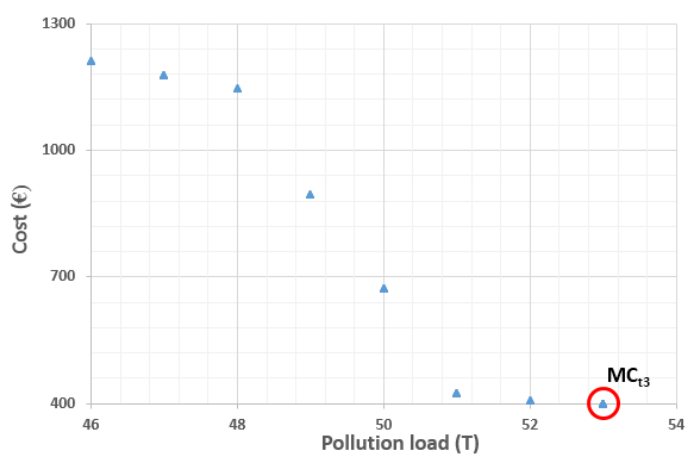

(b) For 30-45 minutes

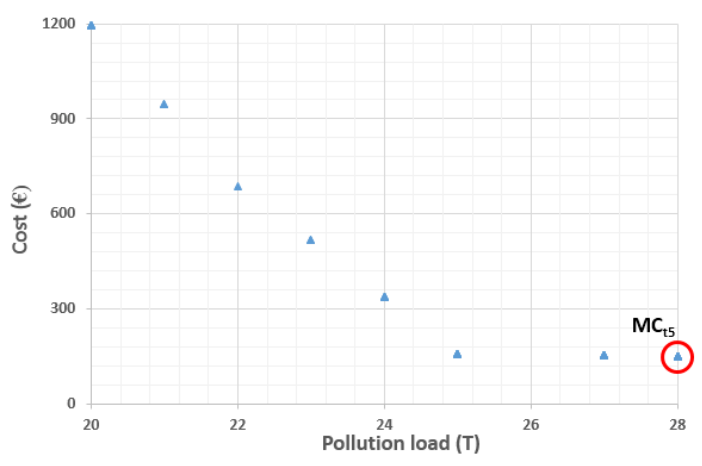

(d) For 60-75 minutes 


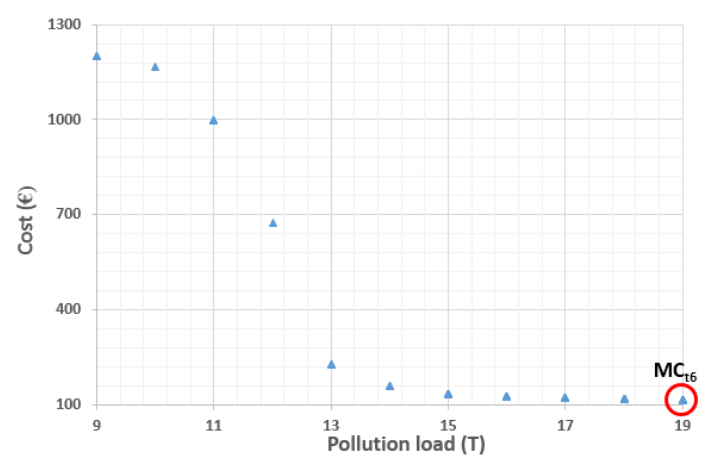

(e) For 75-90 minutes

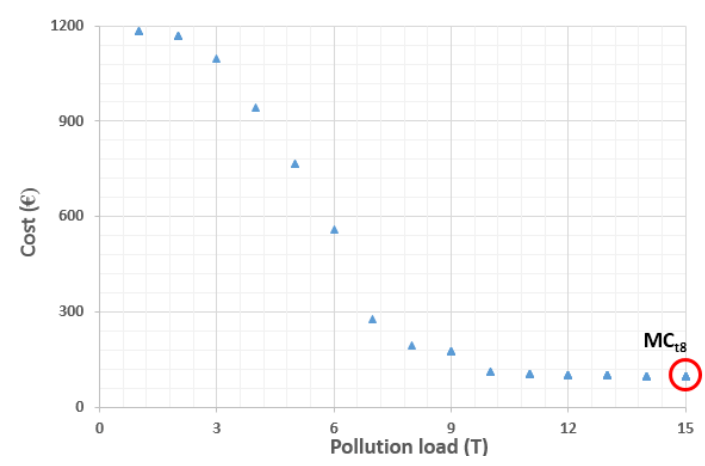

(g) For 105-120 minutes

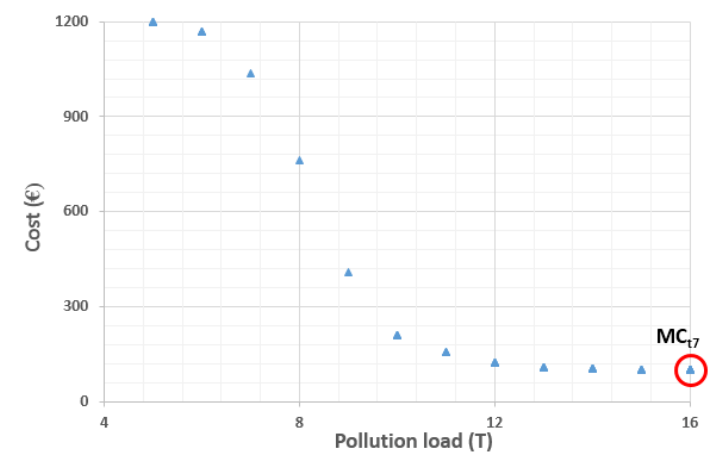

(f) For 90-105 minutes

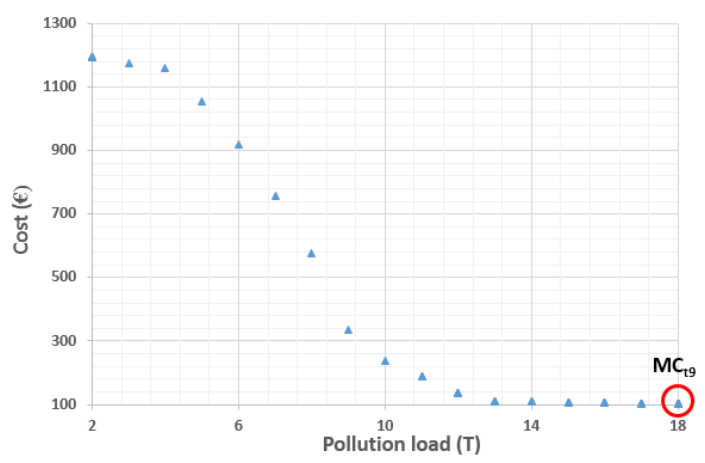

(h) For 120-135 minutes

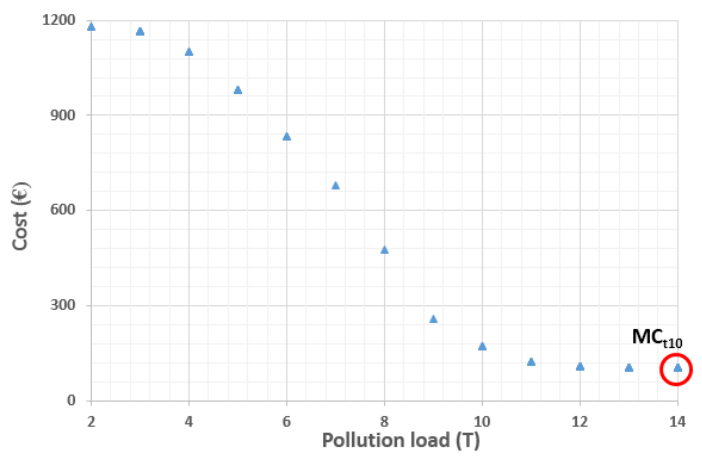

(i) For 135-150 minutes

415 All these Pareto fronts show the usual minimizing behavior or shape. In each time-step, the 416 control settings for the minimum cost solution were extracted and then fed to the next time-step 417 optimization process. Pareto optimal fronts over the time for the minimum pollution load 
418 solution are also similar to the Figures 6a-i (actual figure not shown). However, the Pareto 419 optimal fronts show the minimizing behavior from their curved shapes (i.e. concave up with 420 negative slopes).

421

\section{$422 \quad 5.3$ Robustness of the optimization algorithm}

423 The Figure 7a-b illustrate the Pareto optimal fronts for different initial seeds obtained for 15-30

424 minutes for minimum pollution load solution and at 105-120 minutes for minimum cost solution

425 respectively. Each plot contains optimal fronts from 10 random runs with different initial 426 populations in the genetic algorithm. They clearly show the coinciding effect of the optimal 427 solutions from different initial seeds, but after 100 generations. Therefore, the Figures 7a-b 428 clearly demonstrate the consistency and the stability of the developed genetic algorithm.

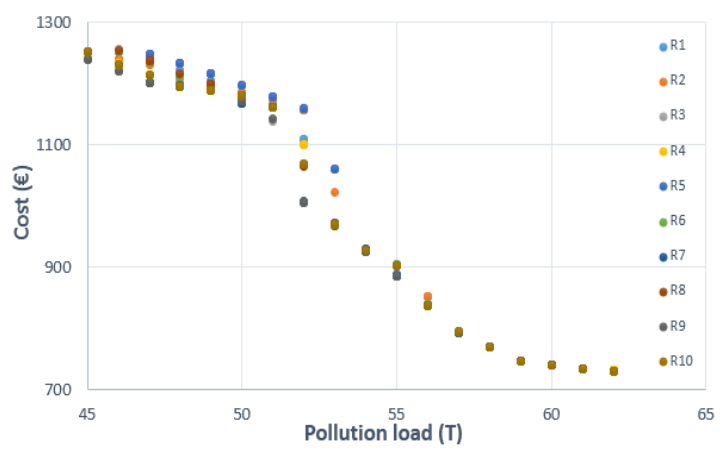

(a) At 30 minutes for minimum pollution

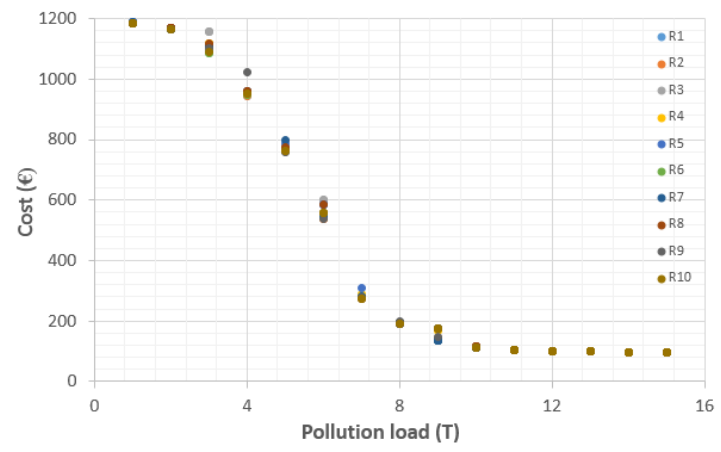

(b) At 2 hours for minimum cost solution load solution

Figure 7 Pareto optimal fronts for different initial seeds

431 The Figure 8 presents the progress of the genetic algorithm in optimal solution obtaining for the third time-step (30-45 minutes). As it can be expected in genetic algorithms in searching optimal 
433 solutions, Figure 8 illustrates a rapid convergence toward the minimum cost solution in 1000

434 function evaluations compared to the minimum cost in 100 function evaluations. However, after

435 that, the cost solution converges to the minimum solution. Nevertheless, if the sewer controller is

436 looking for a solution at a reasonable computational cost, he/she can stop the optimization

437 process at 2000 function evaluations rather than completing 10000 function evaluations in the 438 optimization process. This control possibility is given in Table 1.

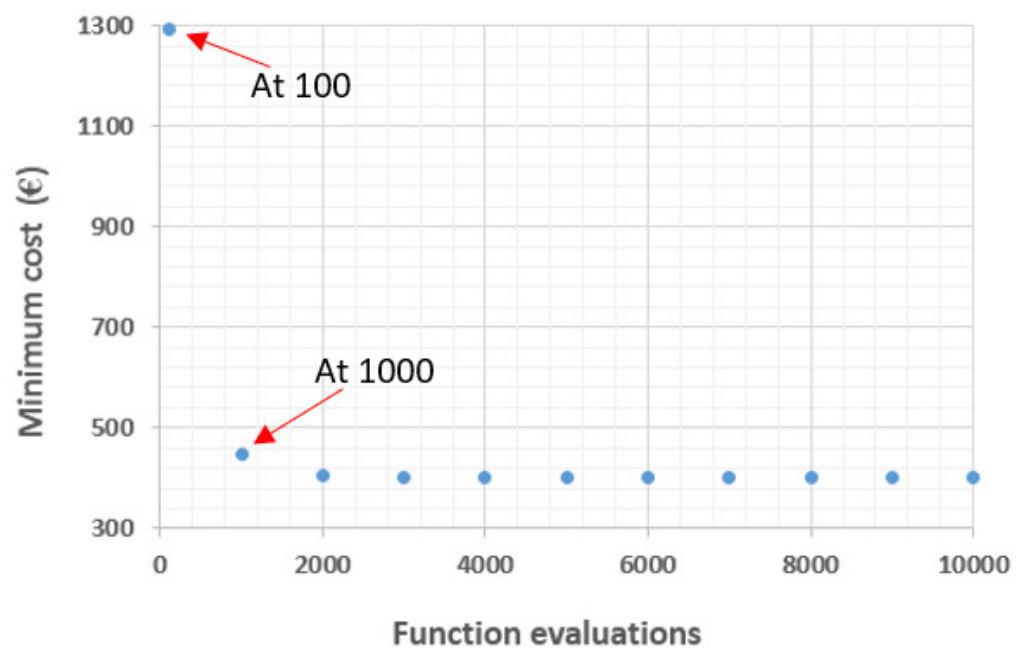

Figure 8 Progress of GA for minimum cost solution at T3

439 However, a similar but an interesting progressing behavior can be observed in minimum 440 pollution load solutions. Unlike, the Figure 8, the process does not show a rapid convergence 441 after the 100 function evaluations. Instead, it shows an increase of the pollution load solution. In 442 fact, even the final optimal pollution load after 10000 function evaluations is numerically higher 443 than the pollution load at 100 function evaluations. The circled solution was further investigated 444 and found that it is an infeasible solution, which was generated initially in the process. Therefore, 445 this solution can be ignored as we are only looking for the feasible solutions. After ignoring the 
446 first infeasible solution, the process shows the usual minimizing convergence. Therefore, the

447 productivity of the developed genetic algorithm in achieving optimal results was achieved.

448

449

\subsection{Comparison of solutions}

450

Table 1 presents the comparison of solutions for 2000 and 10000 function evaluations for the

451 solution presented in Figure 8. The table clearly shows the benefit of obtaining optimal solutions

452 at the premature level of the process. For example, there is no significant difference in cost

453 solutions for $3^{\text {rd }}$ time step at 2000 and 10000 function evaluations ( $€ 404$ and $€ 400$, respectively).

454 In addition, their corresponding pollution loads are the same (53 $\mathrm{T}$ each). Similar observations

455 can be seen for the other time steps as well as the solutions in minimum pollution load solutions.

456

457 Table 1 Comparison of solutions at 2000 and 10000 function evaluations

\begin{tabular}{|l|c|c|}
\hline \multicolumn{2}{|c|}{ Minimum cost solution at $3^{\text {rd }}$ time step } \\
\hline & Cost $(€)$ & Corresponding \\
& & pollution load (T) \\
\hline At 2000 function & 404 & 53 \\
\hline At 10000 function & 400 & 53 \\
evaluations & & \\
\hline
\end{tabular}

458

459 The results after the complete optimization process for the whole storm period revealed that the 460 minimum pollution load solution has pollution load of $\mathbf{1 7 6}$ tons for the total storm period (for 0-

461150 minutes). This pollution load is at a cost of $\mathbf{€ 1 1 6 1 7}$. However, the minimum cost solution 
462 has a cost of $€ \mathbf{1 9 9 7}$ over the total storm period at $\mathbf{2 7 3}$ tons of pollution load. Therefore, the

463 solutions satisfy the aim of the developed objective functions in the multi-objective optimization

464 environment.

465 In addition, the most important finding of this optimization is the dynamic control of the sewer 466 system for the two extreme solutions. In other words, it was found two sets of orifice openings

467 for the minimum pollution load and minimum cost solution over the 150 minutes. The minimum 468 pollution load solution has 7 orifice opening settings for O1- O7. Each orifice opening has a 469 dynamic controlling behavior based on the developed novel optimization algorithm. This 470 dynamic control behavior presents 10 steps of orifice openings for $0-150$ minutes in 15 minute 471 intervals. The similar control settings were found to the minimum cost solution. Therefore, each 472 orifice has 10 control settings over the 150 minutes.

473

\section{$474 \quad 5.5$ Optimal control gate openings}

475 Some of the orifice settings obtained from the optimization process was illustrated in Figure 9.

476 Figure 9a presents the orifice openings for minimum pollution load for $\mathrm{O} 1$ orifice. It clearly 477 shows the dynamic behavior in each time-step. From 15 minutes to 15 minutes, the orifice 478 opening changes. However, the opening heights were not from pre-defined step to step openings; 479 instead the openings can be any height along real number axis from minimum opening to the 480 maximum opening height. In other words, the opening heights are not in the binary axis where is 481 has step responses, but in real number axis with any number of decimals. In comparison, Figure $4829 \mathrm{~b}$ presents orifice opening heights for $\mathrm{O} 1$ orifice for the minimum cost solution. Similar to the 483 minimum pollution load solution case, Figure $9 \mathrm{~b}$ also shows the dynamic behavior of the orifice 484 heights over the 150 minutes. However, after the first 15 minutes, the orifice $\mathrm{O} 1$ is practically 
485 closed until 75 minutes and then slightly opened for 75-90 and 90-105 minutes. It is again closed 486 for 30 minutes and opened for the 135-150 minutes. Therefore, in comparison to the O1 487 openings at Figure 9a, figure 9b shows reduced openings for minimum cost solution. 488 Incidentally, this can be seen bit awkward situation and one would think the two figures have to 489 be swapped for the titles of them. In other words, one would expect to have smaller openings of 490 orifices and then to minimize the sewer overflows from the chamber for the minimum pollution 491 load solution. Similarly, to have larger orifice openings in minimum cost solution which can lead 492 more sewer overflows and then, to reduce the load at treatment plant to minimize the cost. 493 However, it is well noted here that the objective function on pollution load is not totally based on 494 the volumetric flow rate of combined sewer overflow, but it has many other water quality 495 constituents' concentrations. Therefore, this justifies the novelty of the developed optimization 496 algorithm from many other developed algorithms in the basis of volumetric minimization of 497 combined sewer overflow.

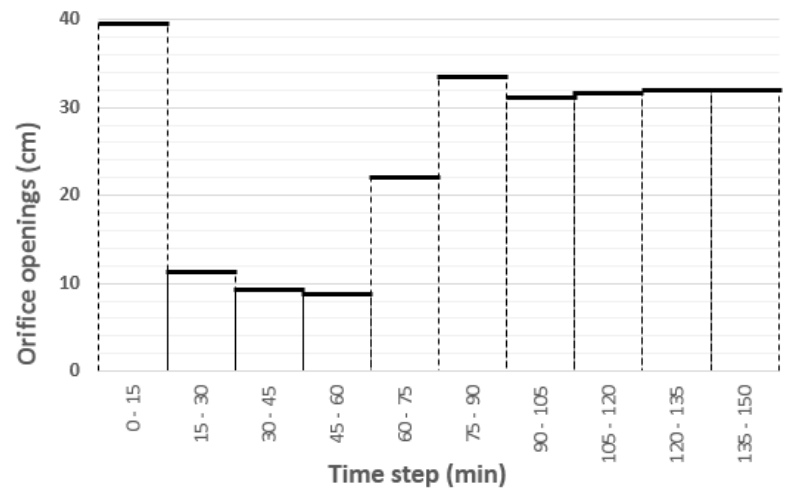

(a) Orifice openings for $\mathrm{O} 1$ for the minimum pollution load solution

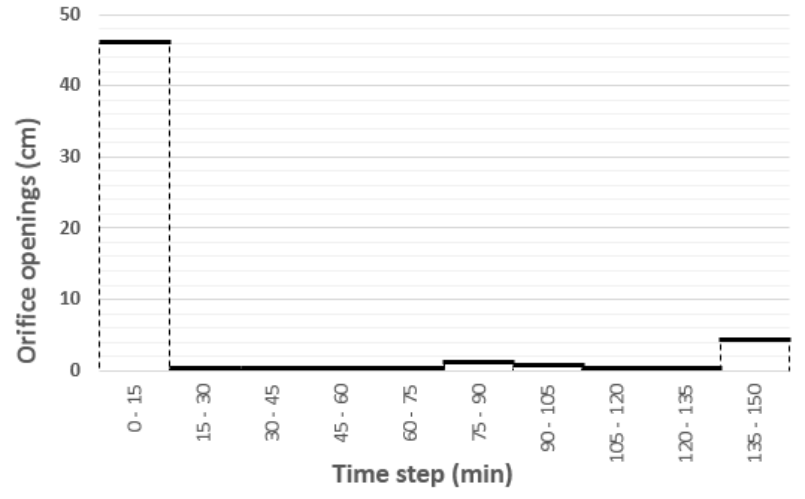

(b) Orifice openings for $\mathrm{O} 1$ for the minimum cost solution 


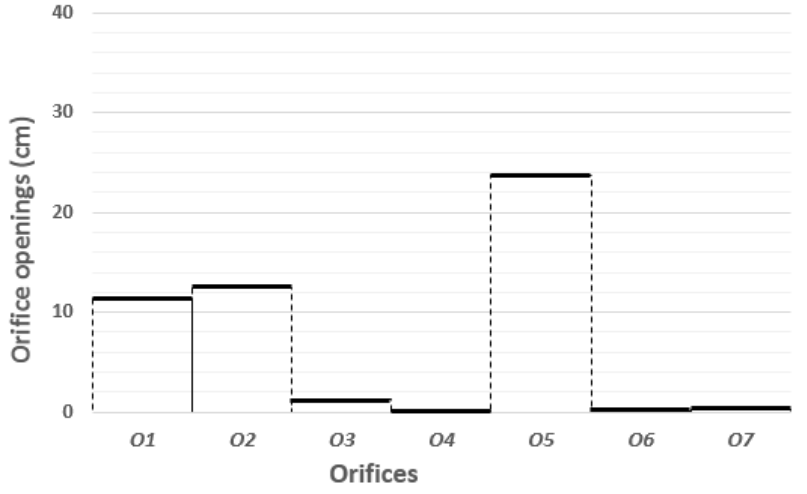

(c) Orifice openings for 15-30 minutes for the minimum pollution load solution

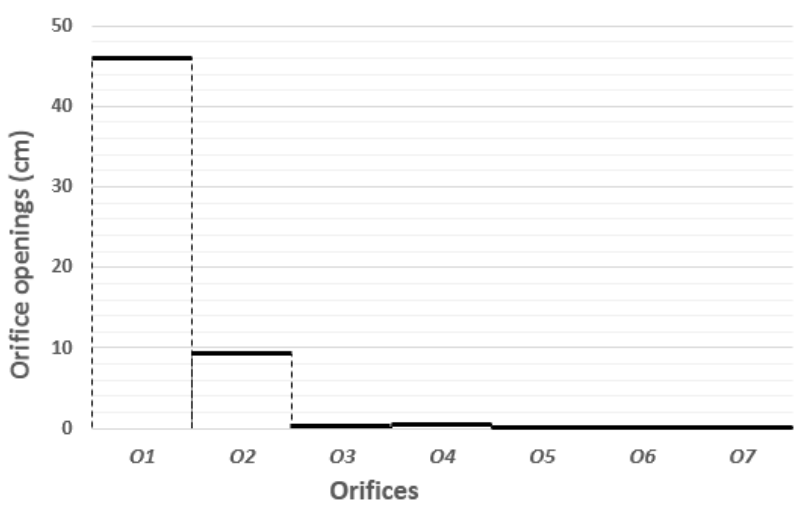

(e) Orifice openings for 15-30 minutes for the minimum cost solution

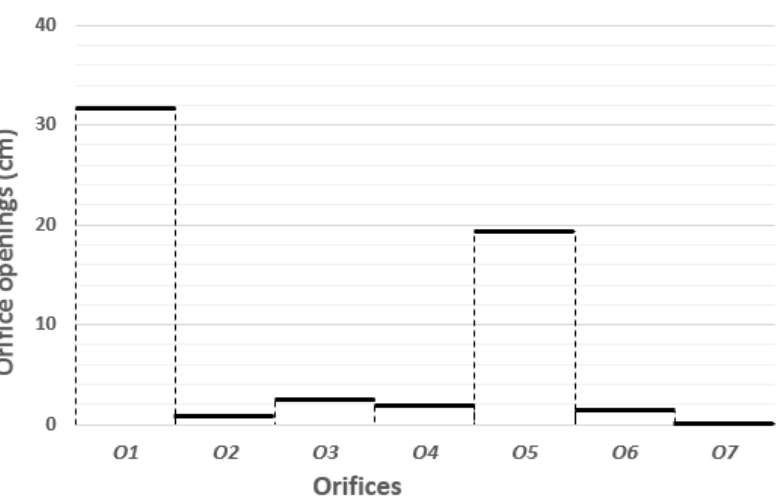

(d) Orifice openings for 120-135 minutes for the minimum pollution load solution

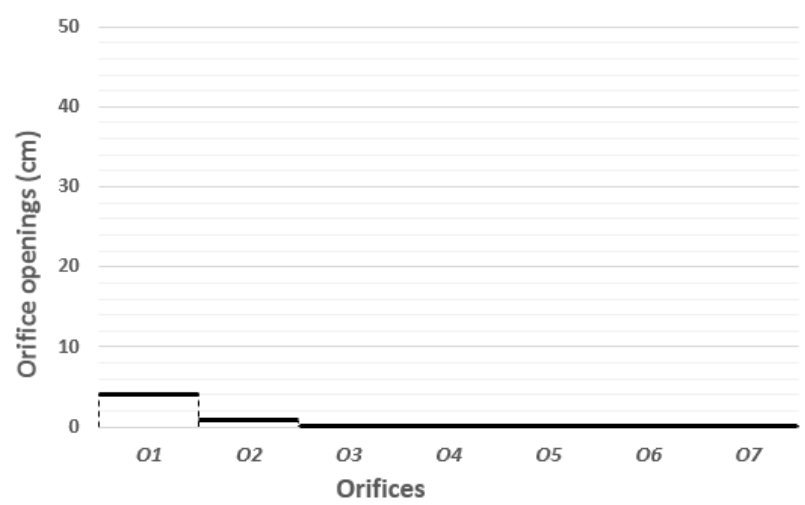

(f) Orifice openings for 135-150 minutes for the minimum pollution load solution

Figure 9 Orifice openings for some of the orifices

Figures 9c and 9d present the orifice openings for 15-30 minutes time step and 120-135 minutes

501 time step for the minimum pollution load solution. The figures clearly show the different control 502 settings (orifice openings) for different orifices (O1 to O7). Therefore, it gives the applicability 503 of the developed algorithm in spatial variation of control settings. In addition, the two figures at 504 different time-steps guarantee the temporal variations of the control settings. Similarly, Figures 
$5059 \mathrm{e}$ and 9f illustrate the orifice openings for 15-30 minutes time step and 135-150 minutes time

506 step for the minimum cost solution. Orifice openings for the same time-step; however, for the

507 two different extreme solutions are given in figures 9c and 9e. They clearly exhibit the 508 applicability of the developed algorithm in different approaches. Therefore, the orifice openings

509 (control settings) can be obtained depending on the desire of the sewer network controller. If the 510 cost is more important, the controller can go for a cost prioritizing solution, whereas, if the 511 pollution load is more important, the controller can look at a solution, which priorities the 512 pollution load. The most important feature is that the controller can even look into these 513 solutions at a smaller time step (even at 15 minutes). In addition, these four Figures 9c-f clearly 514 show the spatial and temporal features of the control algorithm.

5165.6 Hydraulic analysis of selected solutions

517 The Figure 10 presents the flow through sewer conduits for the total storm period for the 518 minimum pollution load solution. These flow rates were obtained from the hydraulic simulations 519 by feeding the control settings found from the optimization analysis. The dashed line on top of 520 each figure (Figures 10a-g) gives the maximum possible flow rate allowed through the sewer 521 conduits. These flow rates were imposed to the control algorithm as the constraints. The figures 522 clearly show that none of the sewer conduits have flow rates more than the allowed flow rates. 523 Those justify the constraint handling ability of the developed algorithm. In addition, they show 524 the temporal variation of the flow rates through sewer conduits. However, the flow rates through 525 sewer conduits are lowered from the controlling algorithm to keep the minimum cost solution. A 526 significant component of the cost function depends on the treated wastewater volume. Therefore, 527 in the minimum cost solution, the algorithm tries to reduce the flow rate to the sewer treatment 
528 plant, thus to reduce the treatment cost. However, in contrast, the flow rates through the conduits

529 for minimum pollution load solution have to be higher than the flow rates shown in Figure 10.

530 More flows are allowed through the conduits to minimize the pollution loads from the CSOs.

531 This observation can be seen in the hydraulic simulated results for the minimum pollution load

532 solution.

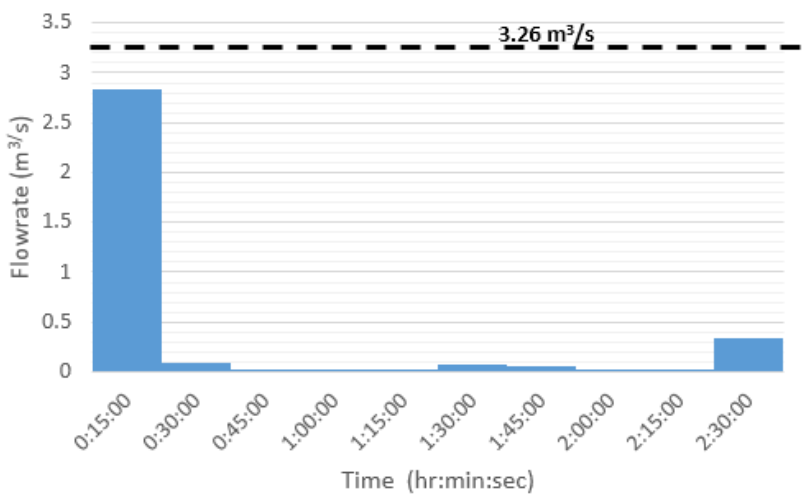

(a) Flow through $C 1$

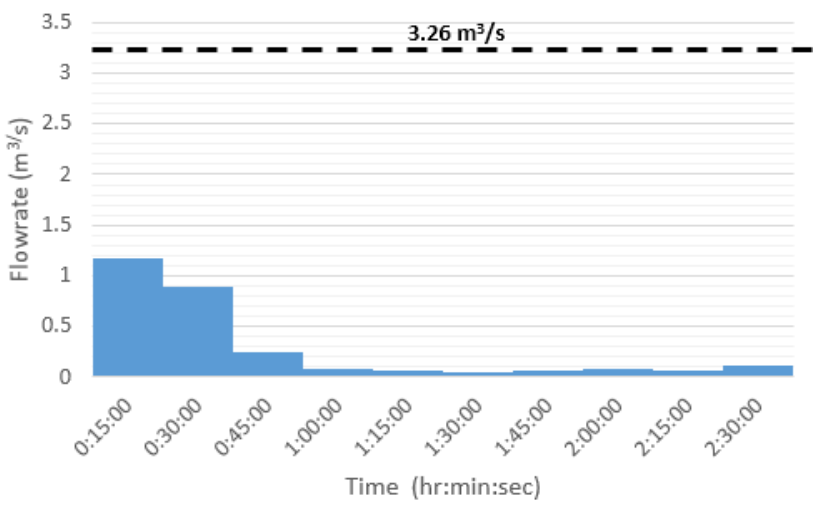

(c) Flow through $C 3$

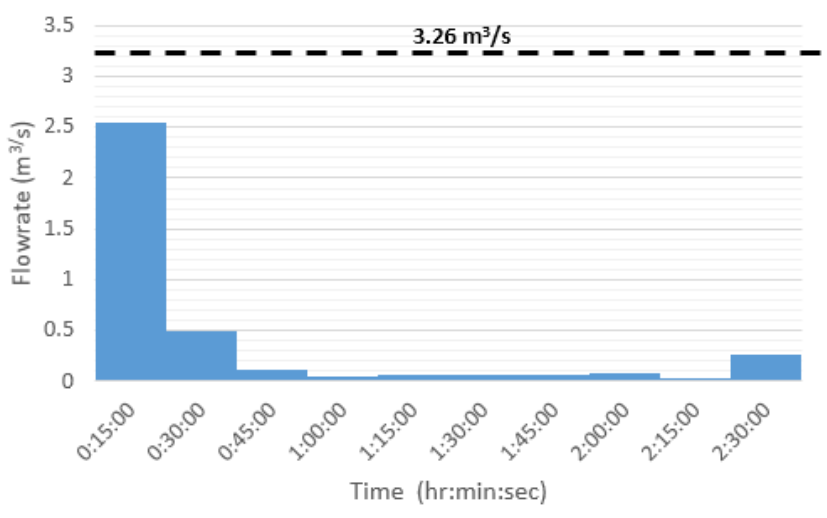

(b) Flow through $C 2$

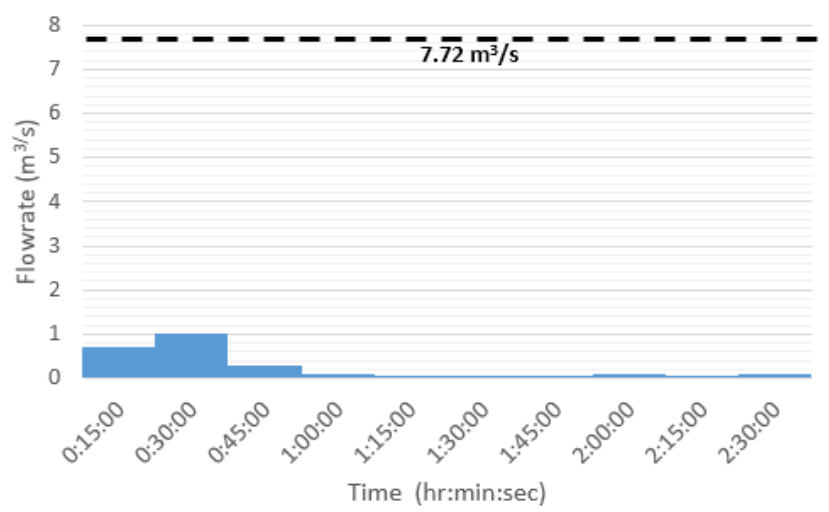

(d) Flow through $C 4$ 


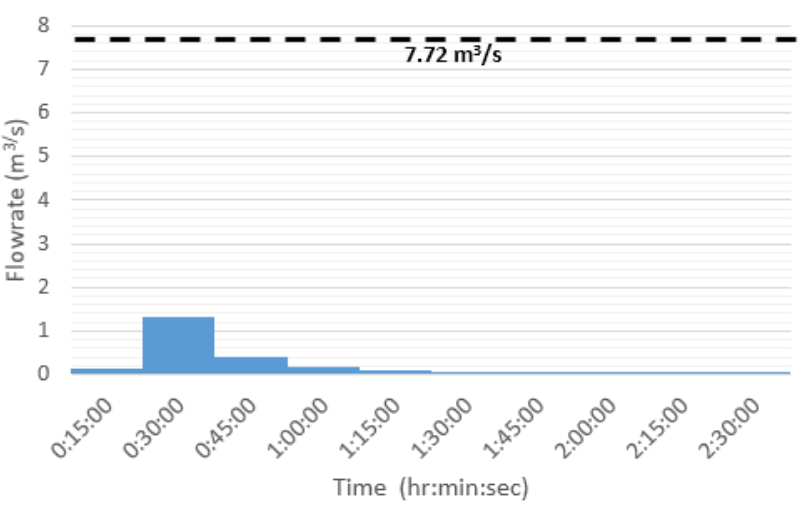

(e) Flow through $C 5$

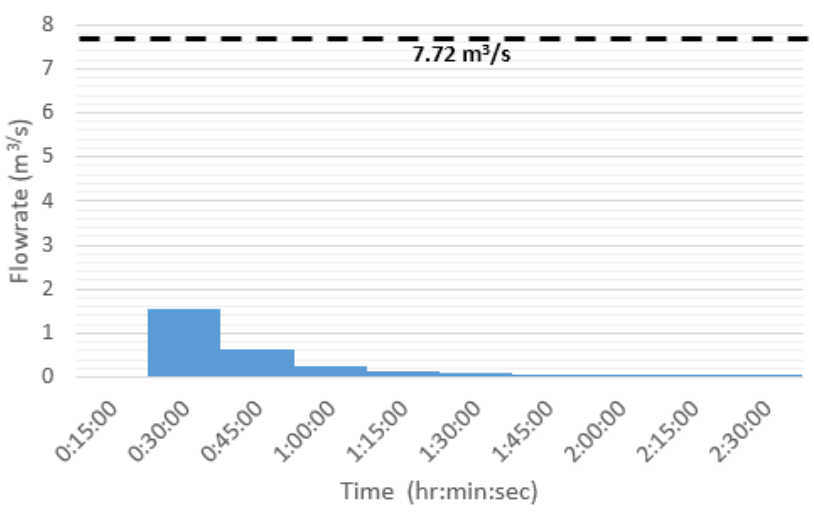

(f) Flow through $C 6$

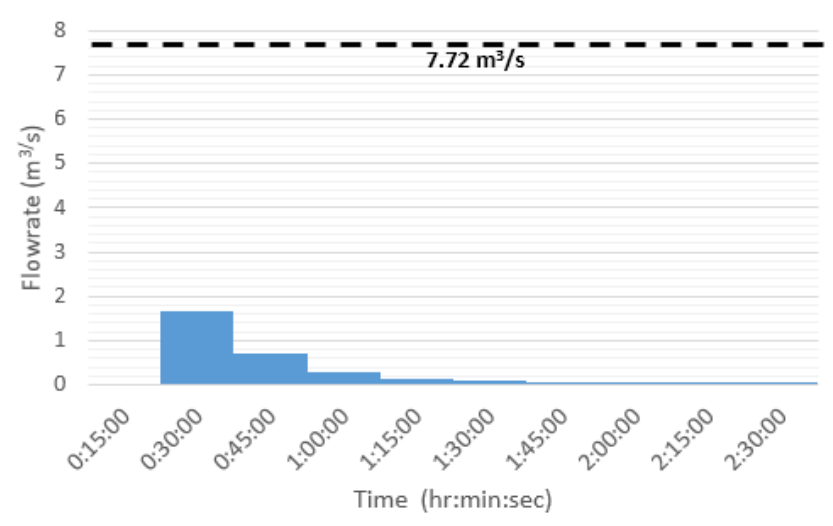

(g) Flow through $C 7$

Figure 10 Flow rates through sewer conduits for minimum cost solution

536 Figures 11a illustrates the wastewater heights in the $\mathrm{T} 1$ sewer chamber for the minimum cost

537 solution. The dashed line shows the maximum height, which the sewer chamber can hold before any CSOs. Therefore, the wastewater heights more than the dashed lines, reflect the CSOs. These

539 sewer chambers acting as another storage tanks (on-line); however, they are with the possibility 540 of having CSOs. The hydraulic importance of having the storage tanks were discussed earlier;

541 nevertheless, they keep a reasonable sewer volume without releasing as CSOs. Therefore, the 542 optimization algorithm tries to have some overflows depending on the volumes or capacities of 
543 the sewer chambers. Figure $11 \mathrm{~b}$ presents the wastewater heights in one of the on-line storage 544 tanks. Similar to the sewer chambers, the dashed lines represent the maximum heights of the 545 storage tank. However, unlike the sewer chambers, the wastewater heights are not exceeding the 546 maximum heights of the storage tanks. Therefore, the algorithm has the ability to keep the role of 547 the storage tanks, i.e. with no CSOs. Even though the storage tanks do not have any CSOs, they 548 are completely filled by the wastewater for the total time. Therefore, the stored wastewater can 549 be released back to the sewer system after the storm.

550 Nevertheless, Figure 11c illustrates the wastewater heights in the off-line storage tank. This off551 line tank works with a hydraulic pump. Interestingly, the storage tank is not completely filled 552 similar to the other two on-line storage tanks. This is because the implementations of new cost 553 function, which includes the cost of pump operation. As it was stated earlier, pump operational 554 cost is a function of the pumped wastewater volume flow rate. Therefore, to minimize pump 555 operational cost, the algorithm minimizes the pumped volume flow rate. Instead, the control 556 algorithm allows to transfer the wastewater to the on-line storage tanks. Similar results can be 557 seen in the minimum pollution load solution wastewater heights. Thus the results clearly 558 revealed that the roles of sewer chambers, on-line storage tanks and off-line storage tanks with 559 improved cost objective functions are satisfied.
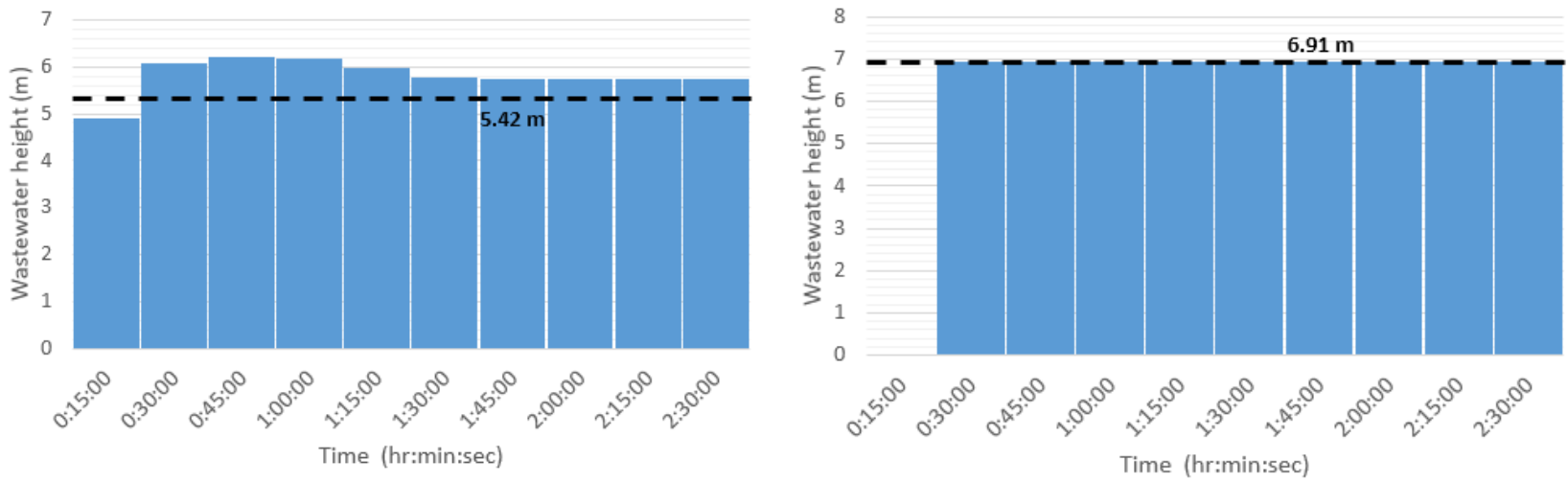
(a) Wastewater height of T1

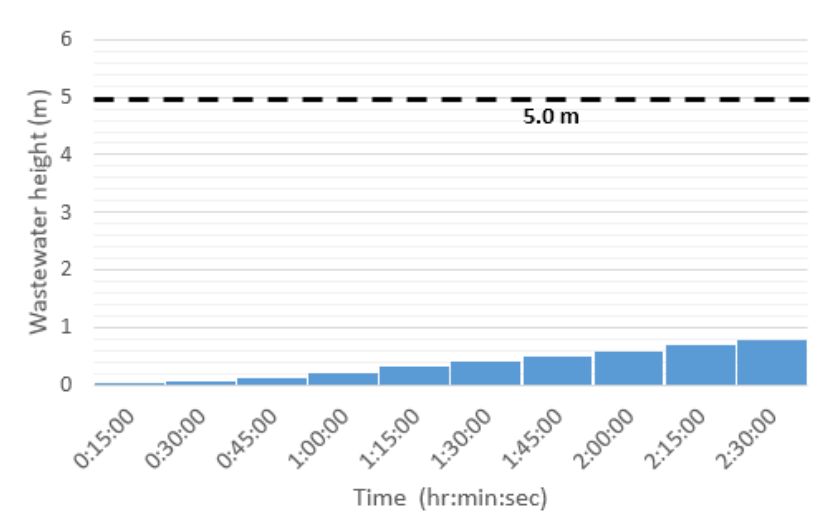

(c) Wastewater height of T10 (b) Wastewater height of T8

Figures 11 wastewater heights in the sewer chambers and storage tanks for the minimum cost solution

562 The control algorithm developed in this study is unique as it can simultaneously minimize two of 563 the most important objectives i.e., pollution load to receiving water from CSOs and the total 564 wastewater treatment and pumping cost of the system. The presented algorithm is the first 565 attempt capable of handling the simultaneous solutions of the multiple objectives and processing 566 the control settings varied in temporal and spatial domains. Unlike most of the other real time 567 optimal controls, this approach finds the hydraulic, hydrological and water quality solutions from 568 full hydraulic simulations. Though this method was applied to an existing network in Liverpool, 569 UK but the optimization algorithm is generic and can be applied anywhere.

\section{Conclusions}


572 A novel algorithm based on multi-objective optimization is presented here to control the

573 combined sewer networks. The algorithm is capable of minimizing the pollution load to the

574 receiving water from the CSOs together with the cost of wastewater treatment and pumping cost

575 in sewer system. The algorithm produces temporally and spatially varied dynamic control

576 settings of the gates in sewer system. These control settings can be obtained as per the

577 requirements of the authorities of the combined sewer system depending on the available

578 financial situation and environmental regulations of the country. Usage of storage tanks in

579 combined sewer systems was justified in the optimal solutions as the algorithm allows the

580 storage tanks to be completely utilized. However, when it comes to incorporate a pump, which

581 adds an operation and maintenance cost that particular storage tank was discouraged by the

582 algorithm. Therefore, the introduced objective functions to the algorithm are satisfying the 583 requirement of the authorities as well as the generic public.

584 Even though the algorithm produces dynamic control settings based on the feedbacks given to 585 the system, the solution algorithm is yet to be applied in the real-time. This is due to the 586 computational cost of the algorithm. The algorithm needs to be improved in simulation times, so 587 that it can be applied real-time. However, the developed control algorithm is well-structured to 588 deal with the receiving water qualities and the cost incurred in the wastewater systems. The 589 approach provides a holistic solution as it incorporates the spatial and temporal variations of 590 flows and pollution concentrations in addition to the non-simplified hydraulic and water quality 591 modeling in combined sewer network. Furthermore, the input parameters for the cost function 592 can be easily improved depending on the economic status of a particular country or concerned 593 area. Therefore, the algorithm would make a greater change in the related applications. 


\section{References}

1. Abo-Sinna, M., Baky, I., 2007. Interactive balance space approach for solving multi-level multi-objective programming problems. Information Sciences. 177, 3397-3410.

2. Aghaei, J., Amjady, N., Shayanfar, H., 2011. Multi-objective electricity market clearing considering dynamic security by lexicographic optimization and augmented epsilon constraint method. Applied Soft Computing. 11, pp. 3846-3858.

3. Alizadeh, M., Nikoo, M., Rakhshandehroo, G., 2017. Hydro-environmental management of groundwater resources: A fuzzy-based multi-objective compromise approach. Journal of Hydrology. 551, pp. 540-554.

4. Anne-Sophie, M., Dorner, S., Sauvé, S., Aboulfadl, K., Galarneau, M., Servais, P., Prévost, M., 2015. Temporal analysis of E. coli, TSS and wastewater micropollutant loads from combined sewer overflows: implications for management. Environmental Science: Processes \& Impacts. 17, pp. 965-974.

5. Bekele, E., Nicklow, J., 2007. Multi-objective automatic calibration of SWAT using NSGA-II. Journal of Hydrology. 341, pp. 165-176.

6. Benedetti L., Bixio D. Vanrolleghem P.A. 2006. Benchmarking of WWTP design by assessing costs, effluent quality and process variability. Water Science and Technolog. 54(10), pp. 95-102

7. Berndtsson, R., Niemczynowicz, J., 1988. Spatial and temporal scales in rainfall analysis — Some aspects and future perspectives. Journal of Hydrology. 100, pp. 293-313.

8. Brokamp, C., Beck, A., Muglia, L., Ryan, P., 2017. Combined sewer overflow events and childhood emergency department visits: A case-crossover study. Science of The Total Environment. 607-608, pp. 1180-1187. 
9. Brunetti, G., Šimůnek, J., Piro, P., 2016. A comprehensive numerical analysis of the hydraulic behavior of a permeable pavement. Journal of Hydrology. 540, pp. 1146-1161.

10. Brzezińska, A., Zawilski, M. Sakson, G. 2016. Assessment of pollutant load emission from combined sewer overflows based on the online monitoring. Environmental Monitoring and Assessment, 188(9), pp.502-511.

11. Carpinelli, G., Caramia, P., Mottola, F., Proto, D., 2014. Exponential weighted method and a compromise programming method for multi-objective operation of plug-in vehicle aggregators in microgrids. International Journal of Electrical Power \& Energy Systems. 56, pp. 374-384.

12. Chang, L., Chang, F., 2009. Multi-objective evolutionary algorithm for operating parallel reservoir system. Journal of Hydrology. 377, pp. 12-20.

13. Charnes, A., Cooper, W., 1977. Goal programming and multiple objective optimizations. European Journal of Operational Research. 1, pp. 39-54.

14. Chen, J., Liu, Y., Gitau, M., Engel, B., Flanagan, D., Harbor, J., 2019. Evaluation of the effectiveness of green infrastructure on hydrology and water quality in a combined sewer overflow community. Science of The Total Environment. 665, pp. 69-79.

15. Congcong, S., Joseph-Duran, B., Maruejouls, T., Cembrano, G., Meseguer, J., Puig, V. and Litrico, X. 2019. Real-Time Control-Oriented Quality Modelling in Combined Urban Drainage Networks. In: The 20th World Congress of the International Federation of Automatic Control. Toulouse, France.

16. Costa, N., Lourenço, J., Pereira, Z. 2011. Multiresponse Optimization and Pareto Frontiers. Quality and Reliability Engineering International. 28(7), pp.701-712.

17. Davis, L., 1991. Handbook of genetic algorithms. Van Nostrand Reinhold, New York. 
18. Deb, K., Pratap, A., Agarwal, S. and Meyarivan, T. 2002. A fast and elitist multiobjective genetic algorithm: NSGA-II. IEEE Transactions on Evolutionary Computation. 6(2), pp.182-197.

19. Dirckx, G., Korving, H., Bessembinder, J., Weemaes, M., 2017. How climate proof is real-time control with regard to combined sewer overflows?. Urban Water Journal. 15, pp. 544-551.

20. Entem, S., Lahoud, A., Yde, L., Bendsen, B., 1998. Real time control of the sewer system of boulogne billancourt - a contribution to improving the water quality of the seine. Water Science and Technology. 37, pp. 327-332.

21. Erbe, V., Risholt, L., Schilling, W., Londong, J. 2002. Integrated modelling for analysis and optimisation of wastewater systems-the Odenthal case. Urban Water Journal, 4(1), pp. 63-71.

22. Fu, X., Goddard, H., Wang, X., Hopton, M., 2019. Development of a scenario-based stormwater management planning support system for reducing combined sewer overflows (CSOs). Journal of Environmental Management. 236, pp. 571-580.

23. García, J., Espín-Leal, P., Vigueras-Rodriguez, A., Castillo, L., Carrillo, J., MartínezSolano, P., Nevado-Santos, S. 2017. Urban Runoff Characteristics in Combined Sewer Overflows (CSOs): Analysis of Storm Events in Southeastern Spain. Water. 9(5), pp. 303-318.

24. Gasperi, J., Zgheib, S., Cladière, M., Rocher, V., Moilleron, R. and Chebbo, G. 2012. Priority pollutants in urban stormwater: Part 2 - Case of combined sewers. Water Research. 46(20), pp. 6693-6703. 
25. Georgaki, S., Vernon, D., Baur, R., Black, D. and Crawford, D. 2018. Extended CSO control storage: what could possibly go wrong?. Water Practice and Technology. 13(1), pp.184-190.

26. Grefenstette, J., 1986. Optimization of Control Parameters for Genetic Algorithms. IEEE Transactions on Systems, Man, and Cybernetics. 16, pp. 122-128.

27. Hermoso, M., García-Ruiz, M., Osorio, F. 2018. Efficiency of Flood Control Measures in a Sewer System Located in the Mediterranean Basin. Water. 10(10), pp.1437-1450.

28. Hofer, T., Montserrat, A., Gruber, G., Gamerith, V., Corominas L., Muschalla, D. 2018. A robust and accurate surrogate method for monitoring the frequency and duration of combined sewer overflows. Environmental Monitoring and Assessment. 190(4), pp. 209226.

29. Hu, C., Teng, C., Li, S., 2007. A fuzzy goal programming approach to multi-objective optimization problem with priorities. European Journal of Operational Research. 176, pp. 1319-1333.

30. Jalliffier-Verne, I., Heniche, M., Madoux-Humery, A., Galarneau, M., Servais, P., Prévost, M., Dorner, S., 2016. Cumulative effects of fecal contamination from combined sewer overflows: Management for source water protection. Journal of Environmental Management. 174, pp. 62-70.

31. Jean, M., Duchesne, S., Pelletier, G., Pleau, M., 2018. Selection of rainfall information as input data for the design of combined sewer overflow solutions. Journal of Hydrology. 565, pp. 559-569.

32. Jee, K., McShan, D., Fraass, B., 2007. Lexicographic ordering: intuitive multicriteria optimization for IMRT. Physics in Medicine and Biology. 52, pp. 1845-1861. 
33. Joseph-Duran, B., Ocampo-Martinez, C., Cembrano, G., 2015. Output-feedback control of combined sewer networks through receding horizon control with moving horizon estimation. Water Resources Research. 51, pp. 8129-8145.

34. Kang, N., Kokkolaras, M., Papalambros, P., 2014. Solving multiobjective optimization problems using quasi-separable MDO formulations and analytical target cascading. Structural and Multidisciplinary Optimization. 50, pp. 849-859.

35. Kim, I., de Weck, O., 2004. Adaptive weighted-sum method for bi-objective optimization: Pareto front generation. Structural and Multidisciplinary Optimization. 29, pp. 149-158.

36. Kim, M., Rao, S., Yoo C. 2009. Dual optimization strategy for $\mathrm{N}$ and $\mathrm{P}$ removal in a biological wastewater treatment plant. Industrial and Engineering Chemistry Research. 48: pp. 6363-6371.

37. Lei, X., Zhang, J., Wang, H., Wang, M., Khu, S., Li, Z., Tan, Q., 2018. Deriving mixed reservoir operating rules for flood control based on weighted non-dominated sorting genetic algorithm II. Journal of Hydrology 564. Pp. 967-983.

38. Leisenring, M., Moradkhani, H., 2012. Analyzing the uncertainty of suspended sediment load prediction using sequential data assimilation. Journal of Hydrology. 468-469, pp. 268-282.

39. Lucas, W., Sample, D., 2015. Reducing combined sewer overflows by using outlet controls for Green Stormwater Infrastructure: Case study in Richmond, Virginia. Journal of Hydrology. 520, pp. 473-488. 
40. Madoux-Humery, A., Dorner, S., Sauvé, S., Aboulfadl, K., Galarneau, M., Servais, P., Prévost, M., 2016. The effects of combined sewer overflow events on riverine sources of drinking water. Water Research. 92, pp. 218-227.

41. Mahmoodian, M., Delmont, O., Schutz, G. 2017. Pollution-based model predictive control of combined sewer networks, considering uncertainty propagation. International Journal of Sustainable Development and Planning. 12(01), pp.98-111.

42. Maneta, M., Pasternack, G., Wallender, W., Jetten, V., Schnabel, S., 2007. Temporal instability of parameters in an event-based distributed hydrologic model applied to a small semiarid catchment. Journal of Hydrology. 341, pp. 207-221.

43. Marler, R., Arora, J., 2004. Survey of multi-objective optimization methods for

44. Marler, R., Arora, J., 2009. The weighted sum method for multi-objective optimization: new insights. Structural and Multidisciplinary Optimization. 41, pp. 853-862.

45. Mauricio-Iglesias, M., Montero-Castro, I., Mollerup, A., Sin, G., 2015. A generic methodology for the optimisation of sewer systems using stochastic programming and self-optimizing control. Journal of Environmental Management. 155, pp. 193-203.

46. Meneses, E., Gaussens, M., Jakobsen, C., Mikkelsen, P., Grum, M., Vezzaro, L. 2018. Coordinating Rule-Based and System-Wide Model Predictive Control Strategies to Reduce Storage Expansion of Combined Urban Drainage Systems: The Case Study of Lundtofte, Denmark. Water. 10(1), pp.76-90.

47. Morales, V., 2016. Urban drainage modeling and evolutionary multiobjective optimization for combined sewer overflows prediction and control, $\mathrm{PhD}$ thesis. University of Illinois at Urbana-Champaign, United States. 
48. Morales, V., Mier, J., Garcia, M., 2015. Innovative modeling framework for combined sewer overflows prediction. Urban Water Journal. 14, pp. 97-111.

49. Müller, T., Schütze, M., Bárdossy, A., 2017. Temporal asymmetry in precipitation time series and its influence on flow simulations in combined sewer systems. Advances in Water Resources. 107, pp. 56-64.

50. Naserizade, S., Nikoo, M., Montaseri, H., 2018. A risk-based multi-objective model for optimal placement of sensors in water distribution system. Journal of Hydrology. 557, pp. 147-159.

51. Nasri, V., Haynes, C., 2015. New tunnel system to eliminate sanitary sewer overflows and control combined sewer overflows in Hartford, Connecticut. Water Practice \& Technology. 10, pp. 282-290.

52. Nie, L., Lindholm, O., Lindholm, G., Syversen, E. 2009. Impacts of climate change on urban drainage systems-A case study in Fredrikstad, Norway. Urban Water Journal. 6, pp. 323-332.

53. Ogidan, O., Giacomoni, M., 2016. Multiobjective Genetic Optimization Approach to Identify Pipe Segment Replacements and Inline Storages to Reduce Sanitary Sewer Overflows. Water Resources Management. 30, pp. 3707-3722.

54. Pennino, M., McDonald, R., Jaffe, P., 2016. Watershed-scale impacts of stormwater green infrastructure on hydrology, nutrient fluxes, and combined sewer overflows in the mid-Atlantic region. Science of The Total Environment. 565, pp. 1044-1053.

55. Qiu, H., Dong, Y., Wang, Y., Gao, L., 2011. Tolerance Optimization Design Based on Physical Programming Methods and PSO Algorithm. Advanced Materials Research. 346, pp. 584-592. 
56. Rathnayake, U., Tanyimboh, T. 2015. Evolutionary Multi-Objective Optimal Control of Combined Sewer Overflows. Water Resources Management. 29(8), pp.2715-2731.

57. Rathnayake, U.S., 2013. Optimal management and operational control of urban sewer systems, PhD thesis. University of Strathclyde, Glasgow, United Kingdom.

58. Rathnayke U.S. (2018) Static optimal control of combined sewer networks under enhanced cost functions to minimize the adverse environmental effects. ISH Journal of Hydraulic Engineering. doi.org/10.1080/09715010.2018.1541765

59. Read G.F. 2004. Sewers replacement and new construction. Elsevier ltd. 1st edition. ISBN 075065083 4. pp. 77

60. Read G.F., Vickridge I. 1997. Sewers rehabilitation and new construction, repair and renovation. Elsevier ltd. 1st edition. ISBN 0340 54472 4. pp. 314

61. Rodriguez, F., Andrieu, H., Creutin, J., 2003. Surface runoff in urban catchments: morphological identification of unit hydrographs from urban databanks. Journal of Hydrology. 283, pp. 146-168.

62. Rossman L.A. 2009. US EPA SWMM 5.0 User's Manual EPA/600/R-05/040, Water Supply and Water Resources Division, National Risk Management Research Laboratory, Cincinnati, USA.

63. Ryu, J., Baek, H., Lee, G., Kim, T., Oh, J., 2015. Optimal planning of decentralised storage tanks to reduce combined sewer overflow spills using particle swarm optimisation. Urban Water Journal. 14, pp. 202-211.

64. Saagi, R., Flores-Alsina, X., Fu, G., Butler, D., Gernaey, K., Jeppsson, U. 2016. Catchment \& sewer network simulation model to benchmark control strategies within urban wastewater systems. Environmental Modelling \& Software. 78, pp.16-30. 
65. Saagi, R., Kroll, S., Flores-Alsina, X., Gernaey, K., Jeppsson, U. 2018. Key control handles in integrated urban wastewater systems for improving receiving water quality. Urban Water Journal. 15(8), pp.790-800.

66. Schertzinger, G., Zimmermann, S., Sures, B., 2019. Predicted sediment toxicity downstream of combined sewer overflows corresponds with effects measured in two sediment contact bioassays. Environmental Pollution. 248, pp. 782-791.

67. Seggelke, K., Löwe, R., Beeneken, T., Fuchs, L. 2013. Implementation of an integrated real-time control system of sewer system and wastewater treatment plant in the city of Wilhelmshaven. Urban Water Journal, 10(5), pp.330-341.

68. Shimoda, M., Azegami, H., Sakurai, T., 1996. Multiobjective Shape Optimization of Linear Elastic Structures Considering Multiple Loading Conditions: Dealing with Mean Compliance Minimization problems. JSME international journal. Ser. A, Mechanics and material engineering. 39, pp. 407-414.

69. Singh, N., 2002. Integrated product and process design: a multi-objective modeling framework. Robotics and Computer-Integrated Manufacturing. 18, pp. 157-168.

70. Snodgrass, W., Dewey, R., D’Andrea, M., Bishop, R., Lei, J., 2018. Forecasting receiving water response to alternative control levels for combined sewer overflows discharging to Toronto's Inner Harbour. Aquatic Ecosystem Health \& Management. 21, pp. 245-254.

71. Soriano, L., Rubió, J., 2019. Impacts of Combined Sewer Overflows on surface water bodies. The case study of the Ebro River in Zaragoza city. Journal of Cleaner Production. 226, pp. 1-5. 
72. Sørup, H., Lerer, S., Arnbjerg-Nielsen, K., Mikkelsen, P., Rygaard, M., 2016. Efficiency of stormwater control measures for combined sewer retrofitting under varying rain conditions: Quantifying the Three Points Approach (3PA). Environmental Science \& Policy. 63, pp. 19-26.

73. Srinivas, N., Deb, K., 1994. Muiltiobjective Optimization Using Nondominated Sorting in Genetic Algorithms. Evolutionary Computation. 2, pp. 221-248.

74. Sun, C., Ritchie, S., Tsai, K., Jayakrishnan, R., 1999. Use of vehicle signature analysis and lexicographic optimization for vehicle reidentification on freeways. Transportation Research Part C: Emerging Technologies. 7, pp. 167-185.

75. Talebi, L., Pitt, R. 2019. Water Sensitive Urban Design Approaches in Sewer System Overflow Management. In: A. Sharma, T. Gardner and D. Begbie, ed., Approaches to Water Sensitive Urban Design Potential, Design, Ecological Health, Urban Greening, Economics, Policies, and Community Perceptions, 1st ed. Amsterdam, Netherlands: Elsevier Publishing Company, pp.140-161.

76. Tao, J., Li, Z., Peng, X., Ying, G. 2017. Quantitative analysis of impact of green stormwater infrastructures on combined sewer overflow control and urban flooding control. Frontiers of Environmental Science \& Engineering. 11(4), pp.11-22.

77. Tavakol-Davani, H., Burian, S., Devkota, J., Apul, D. 2016b. Performance and CostBased Comparison of Green and Gray Infrastructure to Control Combined Sewer Overflows. Journal of Sustainable Water in the Built Environment. 2(2), pp.04015009-1 04015009-12. 
78. Tavakol-Davani, H., Goharian, E., Hansen, C., Tavakol-Davani, H., Apul, D., Burian, S. 2016a. How does climate change affect combined sewer overflow in a system benefiting from rainwater harvesting systems? Sustainable Cities and Society. 27, pp.430-438.

79. Thomas N. 2000. Optimal pollution control models for interceptor sewer systems. PhD Thesis, University of Liverpool, UK.

80. Thomas N., Templeman A., Burrows R. 1999. Optimal pollution control models for interceptor sewers and overflow chambers. International Conference on Computing and Control for the Water Industry. Exeter, UK, pp. 265-278.

81. Thomas N., Templeman A., Burrows R. 2000. Pollutant load overspill minimization of interceptor sewer systems. Engineering Optimization. 32, pp. 393-416.

82. Vezzaro, L., Christensen, M., Thirsing, C., Grum, M. and Mikkelsen, P. 2014. Water Quality-based Real Time Control of Integrated Urban Drainage Systems: A Preliminary Study from Copenhagen, Denmark. Procedia Engineering, 70, pp.1707-1716.

83. Wang, F., Yeh, C., Wu, Y., 1996. PID controller tuning by an interactive multi-objective optimisation method. Transactions of the Institute of Measurement and Control. 18, pp. 183-192.

84. Wang, J., Guo, Y. 2018. An Analytical Stochastic Approach for Evaluating the Performance of Combined Sewer Overflow Tanks. Water Resources Research. 54(5), pp.3357-3375.

85. Wang, M., Liu, S., Wang, S., Lai, K., 2010. A weighted product method for bidding strategies in multi-attribute auctions. Journal of Systems Science and Complexity. 23, pp. 194-208. 
86. Wang, R., Zhou, Z., Ishibuchi, H., Liao, T., Zhang, T., 2018. Localized Weighted Sum Method for Many-Objective Optimization. IEEE Transactions on Evolutionary Computation. 22, pp. 3-18.

87. Wei, Z., Huang, X., Lu, L., Shangguan, H., Chen, Z., Zhan, J., Fan, G. 2019. Strategy of Rainwater Discharge in Combined Sewage Intercepting Manhole Based on Water Quality Control. Water. 11(5), pp.898-911.

88. Weinreich, G., Schilling, W., Birkely, A. and Moland, T. (1997). Pollution based real time control strategies for combined sewer systems. Water Science and Technology, 36(8-9), pp.331-336.

89. Yuan, Y., Ling, Z., Gao, C., Cao, J., 2014. Formulation and application of weightfunction-based physical programming. Engineering Optimization. 46, pp. 1628-1650.

90. Zhang, D., Lindholm, G., Ratnaweera, H. 2018b. Use long short-term memory to enhance Internet of Things for combined sewer overflow monitoring. Journal of Hydrology. 556, pp.409-418.

91. Zhang, D., Martinez, N., Lindholm, G., Ratnaweera, H. 2018a. Manage Sewer In-Line Storage Control Using Hydraulic Model and Recurrent Neural Network. Water Resources Management. 32(6), pp.2079-2098.

92. Zhang, W., Shivpuri, R., 2009. Probabilistic design of aluminum sheet drawing for reduced risk of wrinkling and fracture. Reliability Engineering \& System Safety. 94, pp. $152-161$.

93. Zhao, J., Psychoudakis, D., Chen, C., Volakis, J. 2012. Design Optimization of a LowProfile UWB Body-of-Revolution Monopole Antenna. IEEE Transactions on Antennas and Propagation. 60(12), pp.5578-5586. 
94. Zhao, W., Beach, T., Rezgui, Y. 2017. Automated Model Construction for Combined Sewer Overflow Prediction Based on Efficient LASSO Algorithm. IEEE Transactions on Systems, Man, and Cybernetics: Systems. pp.1-16.

95. Zheng, G., Bi, Q., Zhu, L., 2011. Smooth tool path generation for five-axis flank milling 868 using multi-objective programming. Proceedings of the Institution of Mechanical Engineers, Part B: Journal of Engineering Manufacture. 226, pp. 247-254.

870

96. Zimmer, A., Schmidt, A., Ostfeld, A., Minsker, B. 2015. Evolutionary algorithm enhancement for model predictive control and real-time decision support. Environmental Modelling \& Software. 69, pp.330-341.

873

97. Zimmer, A., Schmidt, A., Ostfeld, A., Minsker, B. 2018. Reducing Combined Sewer Overflows through Model Predictive Control and Capital Investment. Journal of Water 875 Resources Planning and Management. 144(2), pp.04017091-1 - 04017091-11.

876 